IZA DP No. 4894

Estimating the Impact of Immigrants on the Host Country Social Security System When Return Migration is an Endogenous Choice

Murat G. Kirdar

April 2010 


\title{
Estimating the Impact of Immigrants on the Host Country Social Security System When Return Migration is an Endogenous Choice
}

\author{
Murat G. Kirdar \\ Middle East Technical University \\ and IZA
}

Discussion Paper No. 4894

April 2010

IZA

P.O. Box 7240

53072 Bonn

Germany

Phone: +49-228-3894-0

Fax: +49-228-3894-180

E-mail: iza@iza.org

Any opinions expressed here are those of the author(s) and not those of IZA. Research published in this series may include views on policy, but the institute itself takes no institutional policy positions.

The Institute for the Study of Labor (IZA) in Bonn is a local and virtual international research center and a place of communication between science, politics and business. IZA is an independent nonprofit organization supported by Deutsche Post Foundation. The center is associated with the University of Bonn and offers a stimulating research environment through its international network, workshops and conferences, data service, project support, research visits and doctoral program. IZA engages in (i) original and internationally competitive research in all fields of labor economics, (ii) development of policy concepts, and (iii) dissemination of research results and concepts to the interested public.

IZA Discussion Papers often represent preliminary work and are circulated to encourage discussion. Citation of such a paper should account for its provisional character. A revised version may be available directly from the author. 


\section{ABSTRACT \\ Estimating the Impact of Immigrants on the Host Country Social Security System When Return Migration is an Endogenous Choice ${ }^{*}$}

In this paper, I estimate the fiscal impact of immigrants on the German pension insurance (PI) and unemployment insurance (UI) systems when return migration is an endogenous choice. For this purpose, I develop a dynamic stochastic model of joint return migration and saving decisions that accounts for uncertainty in future employment and income and estimate this model using a longitudinal data set on immigrants from five different source countries. I find that allowing for the endogeneity of the return decision makes a substantial difference in the net gain of the PI and UI systems from immigrants. Exogenous return migration - which has been the practice of the literature so far - underestimates the net gain for almost all demographic groups and the amount of underestimation is remarkable for several demographic groups. In addition, age-at-arrival profiles of net contributions of immigrants which form the basis of suggestions on selective immigration policies in the literature - are rotated significantly. Finally, a counterfactual policy experiment in which cash bonuses are provided conditional on return to unemployed immigrants turns out be ineffective in terms of reducing the burden on the state coffers for most demographic groups.

JEL Classification: J61, D91, H55, J65, J68

Keywords: immigrant workers, life cycle models, saving, social security, public pensions, unemployment insurance, public policy

Corresponding author:

Murat G. Kirdar

Department of Economics

Middle East Technical University

Ankara 06531

Turkey

E-mail: kirdar@metu.edu.tr

\footnotetext{
* I am particularly grateful to Kenneth Wolpin for his invaluable guidance and suggestions. I have benefited greatly from advice and comments from Jere Behrman, Petra Todd, and Insan Tunalı, and from many helpful discussions with Dimitri Christelis, Ryo Okui, Nathan Porter, Steffen Reinhold, and Melissa Tartari. I would also like to thank the seminar participants at Bilkent, Koç, METU and Sabancı Universities, University of Mannheim, the University of Pennsylvania, the 6th GSOEP User Conference and the CREAM/TARGET Conference for their valuable comments. All errors are my own.
} 


\section{Introduction}

Many European countries are facing a social security crisis due to an aging native population, rising health costs, and low fertility rates. Börsch-Supan (2000) reports, based on OECD projections, that the ratio of elderly to working age people will increase from 20.6 percent in 1990 to 39.2 percent in 2030 for European member countries. This rise is even higher for Germany, the country this study addresses, where the old-age dependency ratio is expected to increase from 21.7 percent in 1990 to 49.2 percent in 2030 . Immigration could be at least a partial solution to this problem not only because immigrants are more likely to be contributing to the social security system rather than receiving benefits due to their age composition but also because the inflow of immigrants has been high to European countries; e.g., between 1962 and 2005, 800 thousand immigrants entered Germany on average per year. Therefore, immigration is a potential alternative to tax hikes, lower benefits, or delayed age of retirement within the social security system. On the other hand, high rates of unemployment of immigrants resulting from poor economic integration could imply negative net contributions to the social insurance system. For instance, the unemployment rate was 22.2 percent for immigrants in Germany at the end of 2004.

There has been a growing literature on the fiscal impact of immigrants. These studies investigate whether this fiscal impact in net present value terms is positive and whether immigration can have a substantial impact on the fiscal imbalance. However, all of these studies treat return migration as an exogenous factor and approximate the aggregate level of return migration. Exogenous return migration obviously fails to account for the potential selection in the return decision according to immigrants' characteristics. Moreover, the aggregation of return behavior fails to capture the heterogeneity in the level and timing of return migration behavior across various demographic groups. However, the empirical literature on the return migration behavior of immigrants in Germany as well as in other countries reports substantial variation according to their characteristics. ${ }^{1}$

Accounting for return migration properly is very important because the level of return migration of immigrants to their home countries is significant in many host countries. For instance, according to German Federal Statistical Office, between 1962 and 2005, for every 80 in-migrants there were 56 out-migrants on average. ${ }^{2}$ Moreover, the variation in the incidence

\footnotetext{
${ }^{1}$ See, e.g., Kurdar (2009) for Germany, Reagen and Olsen (2000) for the U.S., and Lam (1994) for Canada.

${ }^{2}$ According to Jasso and Rosenzweig (1982), of the 1971 cohort of immigrants in the U.S., the fraction that returned by 1979 could be as high as fifty percent. Aydemir and Robinson (2006) find an out-migration
} 
of return migration over immigrants' duration of residence has important implications for their fiscal impact. For instance, the timing of return migration determines whether immigrants qualify for pension benefits before return or whether they can utilize early retirement schemes that exist in countries like Germany. Finally, the type of selection in return migration is also quite important because whether immigrants become a burden or boon on the social security system depends on whether the returners are selective of the most or least economically successful immigrants.

This paper contributes to the literature by exploring for the first time the fiscal impact of immigrants when return migration is an endogenous choice. For this purpose, it develops and estimates a dynamic model of joint return migration and saving decisions under uncertainty. In the model, immigrants are subject to earnings, employment and preference shocks and they make decisions about whether to stay in Germany for an additional period and how much to save. Using this model that allows for selective emigration and pays due attention to the institutional features in Germany, I calculate the net gain of the German pension insurance (PI) and unemployment insurance (UI) systems from immigrants by country of origin and age at arrival to Germany. Differences in immigrants' life-expectancy as well as in price levels and conditions in the labor market in the home country are incorporated via nationality. The model also incorporates unobserved heterogeneity in a number of permanent characteristics of immigrants like their preferences and labor market ability.

At the same time, developing a structural model that is estimable requires a number of modeling simplifications. First, the model computes the net government gain from male household heads only; those of their family members are ignored as this would require modeling family structure dynamics including fertility decisions. Second, this study examines the net gain of the PI and UI elements of the German social security system only; the third layer of the social security system, health insurance, is not included because participation in this insurance system entitles not only the immigrant himself but also his family to benefits; therefore, the calculation of the time profile of benefits would also require modeling the family structure. Third, there is no calendar year in the model; consequently, the macro-level variables in the model exhibit variation across the source countries but not over time. ${ }^{3}$

rate of 35 percent by 20 years of residence for working-age male immigrants in Canada.

${ }^{3}$ Not having calendar time, I could potentially miss the impact of a time trend in the macroeconomic conditions; e.g. Spain saw an improvement in labor market conditions after joining the EU. However, these changes would be much less important for older generations because most of the Spanish guestworkers were beyond their prime-age when the positive changes in the Spanish labor market took place. 
The model is estimated using the immigrant sample of the German Socioeconomic Panel (GSOEP), which is a longitudinal data set that started in 1984 with an initial sample of immigrants from five different source countries in Germany that include EU member (Greece, Italy and Spain) as well as non-member countries (Turkey, ex-Yugoslavia). Since there is no information on one of the state variables of the model (accumulated savings) in the data set, I use the simulated maximum likelihood technique developed in Keane and Wolpin (2001) which solves the problem of missing state variables in the estimation of dynamic panel data models. ${ }^{4}$ The data set used in the estimation is a stock sample of immigrants in Germany in 1984; therefore, I do not observe the immigrants who already returned by 1984. This structure of the data is also duely addressed in the estimation. The estimation results indicate that the model can account very well for the key features of the micro data according to EU status. In addition, I conduct external validations of the model, including a replication of the return policy of 1983 in which unemployed immigrants were encouraged to return home with cash bonuses, which yield comparable results to the actual changes.

The results show that the net gain of the German PI system from immigrants is positive regardless of age-at-arrival and country of origin and large in magnitude, especially for younger arrivers among non-EU immigrants. An important reason to this positive net gain is that immigrants have a higher average age of retirement than natives because many return to their home countries before they can take advantage of the various early retirement schemes in Germany. The net gain of the UI system is also positive regardless of age-at-arrival for all nationalities except for Turks for whom net contributions are close to zero for most age-atarrival groups. This looks surprising at first given the high unemployment rates of immigrants residing in Germany; however, immigrants who returned had a much lower average likelihood of unemployment during their residence in Germany because unemployment rates were much lower at the early periods in Germany for these immigrants.

Since the key contribution of this paper to the literature on the fiscal impact of immigrants is the inclusion of return migration as an endogenous choice, I also investigate how net gains of the two insurance systems from immigrants change in the case of exogenous return migration that maintains the aggregate hazard rates by country of origin and duration of residence. ${ }^{5}$ Net gains of both PI and UI systems from immigrants fall for almost all demographic groups,

\footnotetext{
${ }^{4}$ There is information on saving flows, though.

${ }^{5}$ Even this includes a higher level of heterogeneity than the previous studies because they do not account for the timing of return migration or variation across countries.
} 
and the fall is substantial for many groups. For instance, net gain of the PI system falls by more than 40 percent from Italian immigrants arriving after age 30 and by about 20 percent from Turkish immigrants arriving before age 40; net gains of the UI system from Turks arriving after age 30 and Italians arriving before age 40 decrease by more than 25,000 DM, an amount that is almost equal to their annual earnings at arrival.

Storesletten (2000) suggests selective immigration policies according to immigrants' age, based on the age-at-arrival profile of net government gain. However, this study also reveals that exogenous return migration causes serious rotations in the age-at-arrival profiles. For instance, while net PI contributions of 18-year-old Spanish entrants increase by 8.7 percent, those of 40-year-old Spanish entrants fall by 27 percent; similarly, while net UI contributions of 40-year-old Turkish entrants fall by 35,231 DM, those of 18-year-old Turkish entrants decrease by only 1,162 DM.

A critical reason to the misestimation of the net government gain by exogenous return migration is that it does not account for the selection in return migration in terms of labor market outcomes. In particular, it does not capture the fact that unemployed immigrants are more likely to return, particularly in earlier periods; and, therefore, it seriously underestimates net contributions. In addition, this counterfactual allows for limited heterogeneity in return migration behavior. While it maintains the level and timing by country of origin, it does not account for the significant variation in the level and timing of return migration as well as in the permanent unobserved characteristics across age-at-entry groups.

I also examine the impact of a counterfactual policy experiment in which cash bonuses are provided to unemployed immigrants conditional on return. Given the high unemployment rates of immigrants in Germany, it could be less expensive for the German government to pay these one-time bonuses rather than unemployment benefits for extended periods of time. However, I find that this policy is not effective in decreasing the burden of unemployed immigrants on the state coffers for most demographic groups. Since unemployed immigrants are more likely to return anyway, the bonus becomes a gift to many immigrants. Moreover, although this policy brings about extra returners, most of these are immigrants who would return in the immediately following periods anyway.

The next section provides background information and reviews the relevant literature. In section 3 , the model and its solution are explained. Section 4 describes the data and presents descriptive statistics. Section 5 covers the estimation method and section 6 presents the estimation results. The impact of immigrants on the German PI and UI systems is discussed 
in section 7 and how this impact changes in the case of exogenous modeling of return decision is left to section 8. A policy experiment in which cash bonuses conditional on return are provided to unemployed immigrants is discussed in section 9. Section 10 concludes.

\section{Background and Relevant Literature}

\subsection{Background Information}

Immigrants constitute a significant proportion of the German population. The German Federal Statistics Office reports that foreigners and their descendants formed 8.9 percent of the German population according to the 2005 microcensus. The level of in-migration to Germany was quite high before 1984, when the initial wave of GSOEP was drawn: on average, 657 thousand immigrants (including ethnic Germans) entered Germany annually between 1962 and 1983, of which sixty-one percent were from the five source countries in this study (German Federal Statistics Office). Most of these immigrants were the guestworkers of 1960's and early 1970's who immigrated to Germany under the bilateral agreements signed by the German government with the source country governments. ${ }^{6}$ As a result of the guestworker recruitment schemes, the share of foreigners in German employment increased from $1.3 \%$ in 1960 to $11.9 \%$ in 1973, and the number of foreigners in Germany in 1973 rose to 4 millions (German Federal Ministry of Interior). In 1973, after the oil price shocks, recruitment of new immigrant workers came to a halt. However, immigration continued mostly in the form of family reunification, and the number of foreigners living in Germany in 1985 reached to 4.4 millions (German Federal Ministry of Interior).

\subsection{Relevant Literature on Motives for Migration Decisions}

Immigration decision can be rationalized in an income-maximizing model where migrants are attracted to the destination because of higher wages there (see, e.g., Sjastaad, 1960; Harris and Todaro, 1970). However, such a model would not be able to explain return migration at the absence of a reversal of wage levels in the source and destination regions. Borjas

\footnotetext{
${ }^{6}$ The initial goal of the guestworker recruitment system was to have these migrants work in Germany for a limited number of years and replace them with new ones once their permit expired. While many of the migrants in fact went back, some stayed. Paine (1974) reports that, in practice, if these guestworkers maintained their employment status in Germany for a few years, they were able to stay.
} 
(1994) explains return migration as a part of optimal life-cycle location decisions. At the time they immigrate, migrants realize that after they acquire physical or human capital in the host country, it may be optimal for them to return because the returns to that type of capital are higher in the home country. The savings that immigrants accumulate in the host country have higher purchasing power in their home country due to the lower prices there. Djajic (1989), Dustmann (1997), and Stark et al. (1997) use this fact as a motivation for return migration. There is empirical evidence on the savings accumulation motive as well; e.g., Yang (2006) reports that return decision of migrants from the Philippines depends on the exchange rate with the host countries. Higher returns in the home country to the human capital acquired in the host country could also rationalize the return migration decision. Another reason for return migration, used by Hill (1987) and Djajic and Milbourne (1988), is that migrants have a preference for location. Return migration may also be the result of unexpected events, either in the host or home country (see, e.g., Berninghaus and SieferVogt, 1992; Tunalı, 2000). Even when it is optimal to immigrate ex-ante, it may be optimal to return after the realization of negative shocks in the host country.

The findings of the empirical literature on immigrants in Germany suggest a saving accumulation motive where migration decisions are induced by the higher purchasing power of savings accumulated in Germany. Kırdar (2009) confirms the saving accumulation conjecture for the same group of immigrants used in this study using the variation in purchasing power parity between the source countries and Germany. In addition, based on a survey of emigrants from Germany in Turkey, Dustmann and Kirchkamp (2002) report that only 6 percent worked as salaried workers after return whereas 51 percent of the returners were self-employed and the other 43 percent were retired, which also suggest a savings motive in immigration to Germany. Similarly, McLean Petras and Kousis (1986) report very limited opportunities in the labor market in Greece for return migrants from Germany. We would expect high saving rates in the host country when the goal of immigration is to accumulate savings. In fact, Kumcu (1989) finds evidence for very high saving rates for Turkish households in Germany. Accordingly, in this paper return migration is rationalized by the higher purchasing power of accumulated savings in the home country. In addition, migrants' preference to live in their home country and unexpected events, in the stochastic nature of the model, also in part explain the return migration decision in the model. 


\subsection{Relevant Literature on the Fiscal Impact of Immigration}

The literature on the fiscal impact of immigrants has largely focused on whether this impact, in net present value terms, is positive and whether it can make a difference in the fiscal imbalance. In this literature, the findings for different countries vary considerably.

The literature on the U.S. reports a positive net fiscal impact of immigration over the life-cycle and generations, but also notes that this impact would do little to change the fiscal imbalance (see, e.g., Auerbach and Oreopoulos, 1999; Lee and Miller, 2000). Storesletten (2000), using a dynamic general equilibrium model, also finds a small fiscal impact of current immigration; however, he claims that it would be possible to sustain the current U.S. fiscal structure by selective immigration.

The evidence from European countries is more mixed. Using the generational accounting framework of Auerbach et al. (1991), Dolores-Collado et al. (2004) for Spain and Mayr (2005) for Austria find a positive fiscal impact of immigrants. On the other hand, Schou (2006) finds that increased immigration would worsen the fiscal balance in Denmark. Storesletten (2003) reports that net contributions of existing immigrants in Sweden are negative; however, he also notes that net contributions of younger immigrants are positive.

Studies regarding the fiscal impact of immigrants in Germany generally point out to a positive net impact, which is in accordance with my findings, as well as potentially important contributions to the fiscal imbalance. For instance, Bönin et al. (2000), using a generational accounting exercise, find that immigrants have a positive fiscal impact in Germany, especially those who arrive at younger ages. Börsch-Supan (1994) finds that immigration at historical levels (300,000 persons per year) makes an important contribution to keeping the public pension system stable. In fact, it reduces the increase that would happen otherwise in the contribution rates to the various social security systems by about 50 percent.

Unlike the above studies, the focus of this paper is on how the fiscal impact of immigrants changes when we account for endogenized return migration. The other key difference of this paper is its empirical content. The findings of this paper are based on parameters obtained from a simulated maximum likelihood estimation of a structural model using a rich longitudinal micro level data set, rather than on calibrated parameters. While my study ignores the descendent of immigrants unlike the above studies, it allows for a richer level of heterogeneity in terms of observed characteristics like country of origin and age at arrival as well as permanent unobserved characteristics on labor market ability and preferences. In fact, no study to my knowledge accounts for the variation in net contributions by country of 
origin despite the fact that many empirical studies note important differences in the return migration behavior across country of origin groups. ${ }^{7}$

\section{Model}

\subsection{Basic Structure}

The basic structure is the discrete choice dynamic programming approach, as outlined in Eckstein and Wolpin (1989). Immigrants choose among a finite set of mutually exclusive alternatives over a finite horizon. The elements of the choice set at each time period are return migration and saving decisions. Immigrants make these decisions under uncertainty: there are random shocks to earnings and preferences, and labor market status follows a stochastic exogenous process. Each period, immigrants realize their labor market status and earnings and decide first whether to stay in Germany or go back to their home country. If they choose to stay, they also make a decision about how much to save.

I model the decisions of male household heads. The model incorporates both observed and unobserved heterogeneity in these immigrants' characteristics. To handle unobserved heterogeneity, I assume that there is a finite number of types of immigrants according to their various permanent unobserved characteristics like preferences and labor market ability, and immigrants within the same type group share the same unobserved heterogeneity. Permanent observed characteristics of immigrants in the model are country of origin and age at arrival, and time-varying observed characteristics include accumulated savings, labor market status, and duration of residence in Germany.

The decision spell starts when an immigrant arrives in Germany and goes until he dies or returns to his home country. Each decision period is taken to be two-years long. Mortality is deterministic and varies according to the country of origin.

\subsubsection{Preferences in Germany}

Immigrants have preferences over consumption $\left(c_{t}\right)$ and location of residence. The utility function, given in (1), has an augmented CRRA form, where $1-\lambda$ is the constant relative risk aversion parameter. The marginal utility of consumption $(\mu)$ varies by age and permanent

\footnotetext{
${ }^{7}$ See, e.g., Kirdar (2009), Borjas and Bratsberg (1996) and Lam (1994) for immigrants in Germany, the U.S., and Canada, respectively.
} 
unobserved preference characteristics (type). $\rho($.$) stands for immigrants' psychic cost of$ living in Germany. This is the difference between the psychic utility in Germany and that in the host country. Immigrants' psychic cost varies by their duration of residence in Germany $(t)$, age at entry $\left(a g e_{0}\right)$ and type. $\eta_{t}^{s}$ is a random shock to preferences.

$$
u_{t}(.)=\mu\left(\text { age }_{t}, \text { type }\right) \frac{c_{t}^{\lambda}}{\lambda}+\rho\left(t, \text { age } e_{0}, \text { type }\right) \exp \left(\eta_{t}^{s}\right)
$$

\subsubsection{Constraints}

There are three constraints, as shown in (2). (i) Given their labor income $\left(y_{t}^{n e t}\right)$, transfer income $\left(y_{t}^{T}\right)$, and asset income $\left(r A_{t}\right)$, immigrants make their consumption and saving decisions. $A_{t}$ denotes asset holdings at period $\mathrm{t}$ and $r$ is the interest rate. (ii) There is a minimum consumption level, $c_{\text {min }}$, which is an institutional feature in this model because this consumption level is guaranteed by the German government through its social assistance for subsistence income program. I allow this subsistence income, which depends on family size, to vary by age and nationality $(z)$. (iii) Borrowing is not allowed. ${ }^{8}$

$$
\text { (i) } c_{t}+\left(A_{t+1}-A_{t}\right) \leq y_{t}^{n e t}+y_{t}^{T}+r A_{t}, \quad \text { (ii) } c_{t} \geq c_{\min }\left(\text { age }_{t}, z\right), \quad \text { (iii) } A_{t} \geq 0
$$

\subsubsection{Labor Market Status in Germany}

There are three potential paths to retirement in Germany: old-age retirement schemes after age 60, disability, and pre-retirement. Old-age retirement is, in turn, possible through four different paths for male workers: 1) One can retire after age 65. 2) Retirement is also possible at age 63 conditional on having a long service life, which is 35 years. 3) Conditional on a qualifying period of at least 15 years, workers who have been unemployed for 52 weeks can retire at age 60.4 ) Retirement after age 60 is possible for disabled workers. ${ }^{9}$ Retirement before age 60 is also possible through disability as well as pre-retirement of workers receiving unemployment compensation.

I assume that all immigrants (male household heads) who are not retired are willing to work. Therefore, at each period, immigrants who are not retired are either employed

\footnotetext{
${ }^{8}$ Immigrants are there to save.

${ }^{9} \mathrm{I}$ assume that this structure is unchanged during the life-cycle of an immigrant and that immigrants expect no change. In fact, there was an upward adjustment in the retirement age with a reform passed in 1992. However, Börsch-Supan and Wilke (2004) report that this reform will be completely in effect only in 2017; therefore, it would not affect most of the workers in my sample.
} 
or unemployed. Retirement is an absorbing state. Labor market status is modeled using a multinomial logit that depends on the labor market status in the previous period, age, age-at-entry to Germany, nationality, and permanent labor market characteristics; thus,

$$
l_{t}=L\left(l_{t-1}, \text { age }_{t}, \text { age }_{0}, z, \text { type }\right)
$$

\subsubsection{Labor Income in Germany}

Gross labor income of an immigrant at period $t, \overline{y_{t}}$, depends on how much human capital he has acquired, $H_{t}$, on the rental price of human capital, $p$, as well as a random productivity shock, $\eta_{t}^{y}$. The level of human capital at any period depends on the years of residence, age at entry, nationality and permanent skill characteristics of the immigrant; thus,

$$
\overline{y_{t}}=p H_{t} \exp \left(\eta_{t}^{y}\right), \quad \text { where } \quad H_{t}=H\left(t, a g e_{0}, z, \text { type }\right)
$$

Three types of social security contributions - pension, unemployment, and health - are paid out of gross labor income. Income taxes, calculated according to the progressive income tax schedule in Germany, are also deducted to find the net labor income, $y_{t}^{\text {net }}$. The details of social security contributions and income taxes are provided in Appendix A.

\subsubsection{Transfer Income in Germany}

Transfer income, $y_{t}^{T}$, includes unemployment benefits, unemployment assistance, pension income, and social assistance for subsistence income. The institutional details of these transfer programs are duely incorporated into the model with a number of simplifications made for the tractability of the model. Only the main features are given here and the details as well as the way these details are taken to model are left to Appendix A.

In Germany, workers who were employed for at least 360 days in the last three years qualify to receive unemployment benefits. This implies that a period of employment in the model, which lasts two years, results in qualification in the consecutive period. Unemployment benefits are equal to two thirds of net employment earnings. Once their entitlement period ends, unemployed workers can still receive another type of benefit, called unemployment assistance, which is about 15 percent less than unemployment benefits. There is no limit on the entitlement duration of unemployment assistance; however, unemployment assistance is means-tested according to asset income. Both unemployment benefits and assistance are net earnings and, therefore, neither social security nor income taxes are applicable. 
German pension insurance system is mandatory to all workers except for the self-employed and those with very low incomes. I assume that these two groups, which constitute a small fraction of the immigrant population, choose to enroll in the PI system. The minimum contribution period to qualify for pension benefits is five years and periods of unemployment are included in the pension contribution period. Since all immigrants are willing to work in the model, the contribution period is equal to the duration of residence in the model. All different paths to retirement effectively pay the same level of benefit. Pension benefits depend on the earnings history and are proportional to the contribution period. ${ }^{10}$ Workers' history of labor market earnings is averaged to generate their relative contribution position. Their contribution period determines the replacement rate applied to the relative contribution position; e.g., for a worker with a 45-year earnings history and average lifetime earnings, pension benefits are equal to 72 percent of his average net earnings while employed.

Workers receive social assistance if their income is not high enough to provide for their basic needs. If the sum of labor and transfer income and asset flows falls below the subsistence income level, the government makes up for the difference.

\subsubsection{Preferences in the Home Country}

Once an immigrant returns to his home country, he exits the sample. As a result, I have no information on his labor market status, income, or saving decisions after return. Therefore, the utility an immigrant receives from spending his remaining lifetime in his home country, $V^{L}\left(\widetilde{\mathbf{S}_{t}}\right)$, is written as a deterministic function of a subset of the state variables at the time of return. These state variables include assets interacted with purchasing power parity $\left(p p p A_{t}\right)$, age, duration of residence and nationality, as shown in (5). This function is explained in detail in Appendix B along with the other functional specifications.

$$
V^{L}\left(\widetilde{\mathbf{S}_{t}}\right)=V^{L}\left(p p p A_{t}, a g e_{t}, t, z\right)
$$

\subsection{The Problem in Recursive Formulation}

Immigrants maximize the present discounted value of their remaining lifetime utility from the age of arrival until they return to their home country or die. The age of mortality is taken as 70 for Turkish, 72 for ex-Yugoslavian and 76 for Italian, Greek and Spanish

\footnotetext{
${ }^{10}$ There are also two other adjustment factors: one for the pension type and one for the average pension level, which determines the income distribution between pensioners and the working population.
} 
immigrants in accordance with the life expectancy of males in these countries calculated for the birth-cohorts in the sample. ${ }^{11}$ The corresponding age of mortality for Germans is $74 .{ }^{12}$

In the case that an immigrant chooses to stay in Germany, he makes a saving decision, $\Delta A_{t}=A_{t+1}-A_{t}$, which is discretized into $K$ distinct levels. ${ }^{13}$ In the objective function given in (6), $d_{\tau}^{k}=1$ if the saving alternative $\mathrm{k}$ is chosen at period $\tau$ and $d_{\tau}^{k}=0$ otherwise. $E$ is the expectations operator, $T$ is the last period in the life-cycle, and $\delta$ is the discount factor (which varies by type), and $\mathbf{S}_{t}$ is the state space at time t. State variables include accumulated savings, labor market status, country of origin, age at arrival, type, and the contemporaneous shocks, the $\eta_{t}$ 's. I assume that $\eta_{t}$ 's are jointly serially independent.

$$
V_{t}^{S}\left(\mathbf{S}_{t}\right)=\max _{\Delta A_{t}^{k}} E\left[\sum_{\tau=t}^{T} \sum_{k=1}^{K} \delta(\text { type })^{\tau-t} u_{\tau}^{k} d_{\tau}^{k} \mid \mathbf{S}_{t}\right]
$$

The solution to the problem in (6) is given by a decision rule that takes the points of the state space to the optimal saving choice. The immigrant compares the maximal value of this problem, $V_{t}^{S}\left(\mathbf{S}_{t}\right)$, with the deterministic value of returning to the home country, $V_{t}^{L}\left(\widetilde{\mathbf{S}_{t}}\right)$, and makes his return decision accordingly. This optimization problem can be recast in the following dynamic programming form.

\footnotetext{
${ }^{11}$ For a given birth cohort, total life expectancy increases by age. Moreover, due to the improvement in health conditions over time, life expectancy profiles over age are at a higher level for later birth cohorts. Because of these reasons, I employ an averaging strategy over the birth cohorts in the sample and over age by taking the life expectancies at age 45 for the 1940 birth cohort according to the data provided in the European Health Statistics of the World Health Organization.

${ }^{12}$ Although Razum et al. (1998) find a lower mortality rate for Turkish residents in Germany than Germans (on contrary to my assumption), they only consider immigrants residing in Germany whereas I am interested in the life-expectancy of all immigrants who ever entered Germany. In fact, they admit that their finding could be resulting from an 'unhealthy re-migration effect'. Moreover, Kibele et al. (2008) point out a methodological problem in this study, which is based on population registries, in the way that they underreport deaths among immigrants because the deaths of immigrants who are resident in Germany but die in their home countries may not be included in the registries. Kibele et al. (2008) use the German Pension Scheme data set, which follows all pensioners very accurately and therefore does not suffer from this problem, and find that the life expectancy of Germans is slightly higher than that of immigrants. Although this finding is more in line with my assumption, their estimate would not give the life-expectancy of all immigrants who ever entered Germany, either, because even though they include immigrants who are resident in Germany but temporarily abroad, they still exclude pensioners with current residence abroad.

${ }^{13}$ These discrete levels of savings are $\pm(6,000,12,000,24,000)$ and $0,+18,000,+36,000$ and $+48,000$.
} 


$$
\begin{aligned}
V_{t}\left(\mathbf{S}_{t}\right) & =\max \left\{V_{t}^{S}\left(\mathbf{S}_{t}\right), V_{t}^{L}\left(\widetilde{\mathbf{S}_{t}}\right)\right\} \\
V_{t}^{S}\left(\mathbf{S}_{t}\right) & =\max _{A_{t+1}}\left\{u\left(c_{t}, \boldsymbol{\eta}_{t}\right)+\delta E_{t} V_{t+1}\left(\mathbf{S}_{t+1}\right)\right\}
\end{aligned}
$$

The expectation in (8) is taken over the joint distribution of the stochastic shocks to earnings and preferences and over the labor market states. In the last period of the problem, the continuation value is a bequest function that depends on the level of assets and type: $V_{T+1}\left(\mathbf{S}_{T+1}\right)=B\left(A_{T+1}\right.$, type). (This function does not introduce any new parameters. As explained in Appendix B, all of its parameters are already included in the value of the returning to home country, $V^{L}\left(\widetilde{\mathbf{S}_{t}}\right)$.)

The solution of this problem is not analytic and a numerical backward solution algorithm is used. This solution involves the calculation of $E_{t} V_{t+1}\left(S_{t+1}\right)$, which requires the calculation of multi-dimensional integrals due to the number of stochastic elements in the model. This is done using Monte-Carlo integration over the joint distribution of shocks at all possible points of the state space for all periods. Since the number of the state space points at which the problem needs to be solved depends on the decision horizon, I take the decision period as two years to alleviate the computational burden.

\section{Data}

The data set used in this study is the German Socio-Economic Panel (GSOEP). This is a longitudinal data set of households in Germany that contains an oversampled group of immigrants from five Mediterranean countries, of which three are members of the European Union (Greece, Italy and Spain) and two are not (Turkey and Ex-Yugoslavia). I use the 2000 version of the GSOEP, which is conducted annually from 1984 to 2000. It is important to note that this is not a random sample of immigrants from these five source countries who enter Germany but rather a stock-sample of them in 1984 with follow-up. The initial sample in 1984 contains 1326 households.

I analyze the behavior of male immigrants who made the choice to immigrate to Germany. Therefore, I restrict the sample to households with a first-generation immigrant male. A first-generation immigrant is defined as one who entered Germany after the age of 18 . 1055 households have a first-generation male household head. In addition, nine households have a first-generation male whose family status is registered as a spouse. Defining these 
nine males as household heads, I end up with 1064 households with a first-generation male household head. Two of these who entered Germany after the age of fifty are dropped. Consequently, the final sample contains 1062 male first-generation household heads, of which 312 are Turkish, 234 are ex-Yugoslavian, 156 are Greek, 212 are Italian, and 148 are Spanish. ${ }^{14}$

The surveys on these household heads contain detailed information on return migration, saving, labor market status and income. Return migration is reported as "moved out of country" in the sample by information gathered from other family members, relatives, neighbors, and so forth. Saving information is available only after 1991. Immigrants are asked about their average monthly saving. However, the data are censored below at zero because respondents are not asked about their dissaving. ${ }^{15}$ Information on immigrants' labor market status is available from their year of entry to Germany whereas income information is available after 1983, including amounts for each type of income. In accordance with the sources of income in the model, I use labor income, unemployment benefits and assistance, pension benefits, subsistence income, and asset flows components. All income data are reported in 1998 prices. All four pieces of information-return migration, saving, labor market status, and income-are aggregated to two-year intervals in accordance with the solution of the dynamic model.

Macro data are also used in the estimation. These are the purchasing power parity (ppp) between the source countries and Germany and expected wages in the source countries. In calculating the expected wages, unemployment rates and the replacement rates of unemployment benefits in the source countries are taken into consideration. Since there is no calendar year in the model, averages of time series data from 1975 to 2000, are taken. The macro data, displayed in Table 1, show that both ppp and expected wages display significant variation across the source countries; e.g., compared to that in Germany, purchasing power is 120 percent higher in Turkey whereas it is only 30 percent higher in Italy.

\footnotetext{
${ }^{14}$ In addition, there are 28 other first-generation males who enter the sample later, after 1984, mostly through marriages to the initial members of the sample. However, since this group is selected into the sample through their higher propensity to marry, I exclude this group.

${ }^{15}$ GSOEP has also information on remittances and how much of these remittances are used for saving purposes. The assumption I make in calculating saving data is that if an immigrant make remittances in the form of savings, he also includes this amount when he answers the question on his average monthly saving. In fact, both the GSOEP data and a study by Koç and Onan (2004), using data from Turkey, show that most of the remittances are used for consumption purposes.
} 


\subsection{Descriptive Statistics}

\subsubsection{Immigrant Characteristics}

Table 2 presents descriptive statistics for the immigrant population from the five countries in the sample in 1984. Almost two thirds of this population are non-EU immigrants: Turks constitute 42.2 percent and ex-Yugoslavians 23.3 percent of this population. The population shares of EU source countries are smaller: 9.2 percent for Greece, 19.8 percent for Italy, and 5.6 percent for Spain. Immigrants in this population were relatively young at arrival: the mean age at arrival is 27.4 years. Age at arrival is quite similar across nationalities, except for Italian immigrants whose average age at arrival is lower at 25 . The average year of immigration is close to 1970; i.e., in the initial wave of the survey in 1984, these immigrants had been in Germany on average for 14 years. Yet, for all nationalities there are immigrants who arrived in the early 1980's, whose outcomes we can observe starting from early years of residence. However, due to their smaller number the data are sparser at early years of residence, except for labor market outcomes which include retrospective information. The mean value for the duration of residence until the last survey is almost 23 years, which implies that the mean value for the year of last survey is roughly 1993.

\subsubsection{Labor Market Outcomes, Income, and Saving Choices}

Here, I present immigrants' labor market outcomes, income, and saving choices over their duration of residence in Germany. The figures in this section are going to be used in validating the model. In these figures, an immigrant can show up many times as long as he does not return; therefore, the figures are influenced by the effects of return migration dynamics.

The first panel of Figure 1 illustrates the percent unemployed immigrants over duration of residence by EU status. For both EU groups, the percentage of unemployed immigrants rises remarkably by duration of residence. The upward profile is much more prominent for non-EU immigrants, though: at 30 years of residence while the unemployment rate of EU immigrants is around 10 percent, it is almost 30 percent for non-EU immigrants. The fraction of retired immigrants by duration of residence and EU status is displayed in the second panel of Figure 1. More than 20 percent of non-EU immigrants and more than 10 percent of EU immigrants are already retired before age 60 . The fraction of retired immigrants rises substantially at age 60 and after age 65 in accordance with the rules of the German retirement system.

The first panel of Figure 2 presents the income profiles over duration of residence by EU 
status. The income profiles are rather flat for both EU groups. Per period income levels are slightly higher for EU immigrants: while they lie roughly between sixty and seventy thousand DM for non-EU immigrants, for EU immigrants they average around seventy thousand DM except for the very early and late periods. (One DM was roughly equal to 0.6 U.S. dollar at the end of 1998.) The fact that immigrants' income levels are relatively constant over time despite steadily rising unemployment rates seems to be surprising. However, as unemployment rates of immigrants were rising in Germany, real wages were also increasing. While the real wage rate in Germany was 74 percent of that in the U.S. in 1984, it was 184 percent of that in the U.S. in 1995 (U.S. Bureau of Labor Statistics). Moreover, the rise in asset flows over time-along with the rise in the accumulated assets-also in part compensate for the decline in average income due to a higher likelihood of unemployment.

Mean saving profiles by EU status are illustrated in the second panel of Figure 2. ${ }^{16}$ The most salient feature of the figure is the difference in the shape of the profiles according to EU status. The saving flow of non-EU immigrants goes down from a level well above 10,000 $\mathrm{DM}$ in the 5th period to a level below 5,000 DM after the 15th period. On the other hand, the saving profile of EU immigrants is relatively flat at a level just below 10,000 DM until the few last periods.

\subsubsection{Return Migration Choices}

The Kaplan-Meier hazard function for return migration choices, which is also going to be used in the validation of the model, is estimated by duely addressing the stock-sample structure of the data. Since the sample represents the immigrant population from five countries in Germany in 1984, it is more likely to include immigrants with longer spells of residence in Germany. Therefore, I use the standard techniques in duration analysis to handle lefttruncation-there is late entry into the risk set but we know the time at which the entry to the risk set takes place-in generating the hazard functions. This technique handles the 'selection bias' resulting from the higher likelihood of inclusion of immigrants with longer spells of residence by using the information on the elapsed time between the year of immigration and the year of first interview. According to this, for instance, an immigrant who arrives in Germany in 1974 enters the risk set at 10 years of residence and contributes to the hazard function after this time whereas an immigrant who arrives in Germany in 1964 enters the risk set at 20 years of residence. This implies that when I compute the Kaplan-Meier hazard

\footnotetext{
${ }^{16}$ Since the saving data is available only after 1991, the earliest saving observation is at the fifth period.
} 
functions, I assume that there are no direct year-of-arrival effects; i.e., holding all other characteristics constant two immigrants who arrive in Germany in two different years would display the same return migration behavior. ${ }^{17}$

The smoothed Kaplan-Meier hazard contributions according to EU status, presented in Figure 3, reveal significant differences between the EU groups. ${ }^{18}$ In fact, a statistical test of the equality of the survivor functions is rejected: EU immigrants are more likely to return. There are important differences in the timing of return as well. EU immigrants are much more likely to return at earlier periods. Their hazard function exhibits a precipitous decline in the first five periods, after that it is relatively flat at a six percent level until late periods when it slightly increases again as immigrants reach retirement age. On the other hand, non-EU immigrants' hazard function has a hump shape that peaks at around the 7th to 8th periods (15 years of residence) at a level of five and a half percent per period.

\section{Estimation Method}

One of the endogenous state variables in the model, accumulated savings, is not observed. Therefore, I use the method introduced by Keane and Wolpin (2001) for estimating dynamic panel data models with unobserved endogenous state variables. Typically, the calculation of the probabilities that form the likelihood function requires conditioning on past state variables (see, e.g., Keane and Wolpin, 1997). The novel feature of this method is that it removes the need to calculate these conditional probabilities. The basic idea of this estimation method is to minimize the distance between the simulated and reported outcomes. A measure of the distance between the simulated and reported outcomes is constructed by assuming that the observed outcomes are measured with error. ${ }^{19}$ By acknowledging the existence of measurement errors for the continuous outcomes and classification errors for the discrete ones, I incorporate into the likelihood calculation, for instance, the fact that when a migrant is observed as employed, there is a positive probability that he was in fact

\footnotetext{
${ }^{17}$ In fact, a test of equality of the survivor functions according to year of arrival is not rejected. This test is done under stratification according to country of origin because of the variation in the country of origin composition of year-of-entry groups.

${ }^{18}$ This is based on a weighted kernel smooth of estimated hazard contributions. A relatively narrow bandwidth is chosen in order not to smooth to much.

${ }^{19}$ Keane and Sauer (2003) show that this estimator has good small sample properties in a more extended setting.
} 
unemployed but his employment status was classified incorrectly in the data.

Following Heckman and Singer's (1984) non-parametric modeling of unobserved heterogeneity, I assume that there is a finite number $(\mathrm{K})$ of type groups. Each individual i may belong to any of these type groups, 1 to $\mathrm{K}$. It is the probability of being a certain type that differs across individuals. Therefore, when I generate the simulated outcomes for an individual, I do it separately for each type. Using the initial state variables and the sequence of random shocks drawn for each individual, I simulate $\mathrm{N} / \mathrm{K}$ migration and saving choice histories, $D^{s i m}=\left\{\left\{m_{t},\left(A_{t+1}-A_{t}\right)\right\}_{t=1}^{T_{i}}\right\}_{n=1}^{N / K}$, and histories for labor market status and earnings, $X^{s i m}=\left\{\left\{l_{t}, y_{t}\right\}_{t=1}^{T_{t}}\right\}_{n=1}^{N / K}$, for each type of each individual. In the construction of these simulated histories, the initial value of accumulated savings is taken as zero and labor market status before arrival is taken as "employed". ${ }^{20}$

The part inside the parenthesis in (9) gives the simulator for type $\mathrm{k}$ of individual $\mathrm{i}$, which is the probability of observing the reported outcomes, $O_{i}^{o b s}=\left(D_{i}^{o b s}, X_{i}^{o b s}\right)$, conditional on the simulated outcomes averaged over the $\mathrm{N} / \mathrm{K}$ simulated histories. This simulator is conditional on staying in Germany until 1984 because the sample contains only immigrants who stayed in Germany until 1984. In equation $(9), I\left(\left\{m_{i n t}\right\}_{t=1}^{t_{i, 1983}}=0\right)$ indicates that the migration choice from the first period in Germany until the period in 1983 for individual i was to stay. Then, the likelihood contribution for this individual, $\widehat{P}\left(O_{i}^{o b s}\right)$, is calculated as the weighted average of these simulators for each type over the probabilities of his belonging to each type, which is shown by $\kappa_{i, k}$ in $(9) . \kappa_{i, k}$ is specified as a multinomial logit with age at entry and country of origin as arguments: $\kappa_{k}=\kappa\left(a g e_{0}, z\right)$. Appendix $\mathrm{C}$ presents the details of the estimation method, including the definitions of classification and measurement errors and the details of the calculation of $P\left[\left(O_{i}^{o b s}\right) \mid\left(O_{i k n}^{s i m}\right)\right]$. Note that the estimation method duely addresses the censored structure of the saving outcome in the data.

$$
\widehat{P}\left(O_{i}^{o b s}\right)=\sum_{k=1}^{K} \kappa_{i, k}\left(\frac{\sum_{n=1}^{N / K} P\left[\left(O_{i}^{o b s}\right) \mid\left(O_{i k n}^{\text {sim }}\right)\right] I\left(\left\{m_{i t}\right\}_{t=1}^{t_{1983}}=0\right)}{\sum_{n=1}^{N / K} I\left(\left\{m_{i t}\right\}_{t=1}^{t_{1983}}=0\right)}\right)
$$

\footnotetext{
${ }^{20}$ The former assumption, I believe, is a parsimonious one as most of these immigrants were unskilled young people from poor regions that chose to work in a foreign country. Since employment transition is a first-order Markov chain and most immigrants were employed in their first period in Germany, the assumption that everybody was employed before entry would have very little impact on the results.
} 


\section{Estimation Results}

\subsection{Parameter Estimates and Interpretation of Types}

The estimated parameters and their standard errors are presented in Appendix D. All parameter estimates are sensible and have the expected signs; e.g., the marginal utility of consumption is lower at early and later ages-when family size is smaller-, psychic cost decreases over time and increases in age at arrival, and country of origin parameters are in line with the general attractiveness of these countries-the highest for Italy and lowest for ex-Yugoslavia. I am not interested in the estimated value of any parameter per se; however, here I will discuss one interesting finding regarding the coefficient of CRRA utility function.

The estimated coefficient of the CRRA utility function is 0.63 ; i.e., the coefficient of relative risk aversion is 0.37 , which is low compared to what the literature has generally uncovered so far. For instance, Gooree et al. (2003) report a number of experimental studies that estimate a risk aversion parameter that is around 0.5. My estimate implies a high level of willingness to substitute consumption intertemporally and a low level of relative prudence. Normally a high level of prudence is required so that young people do not borrow despite a rising lifetime income profile. However, with borrowing constraints-which are included in my model-a high level of prudence may not be needed anymore. In fact, Keane and Wolpin (2001), also find a low coefficient of relative risk aversion in their model, which also accounts for borrowing constraints. My estimation results indicate that these immigrants are willing to save a lot and endure relatively low levels of consumption after their arrival to Germany to take advantage of the higher purchasing power of their accumulated savings after returning to their home country. This behavior is more likely to come from people with a high level of willingness to substitute consumption intertemporally.

In a migration model, it is quite important to understand the differences across immigrant types because the distribution of types changes over time due to the differences in their return migration behavior. I assumed that immigrants differ in terms of their unobserved permanent characteristics with respect to their psychic costs of living in Germany, discount factor, marginal utility of consumption, labor market ability, and the way the value of returning to their home country varies with respect to their accumulated savings. Due to the variation in these characteristics, different types display quite different return migration behavior. Figure 4 displays the hazard functions for all immigrants by type. While type 3s are stayers, type 1s, 2s, and $4 \mathrm{~s}$ can be classified as returners. Significant differences exist 
in the return behavior of these returner types as well. Type 4s have the highest the hazard rates and their hazard function is rather flat over time. While both type $1 \mathrm{~s}$ and type $2 \mathrm{~s}$ have upward sloping hazard functions, the hazard function of type $2 \mathrm{~s}$ rises earlier. Another important distinguishing feature across types is their unemployment rates. Type $4 \mathrm{~s}$ have much higher unemployment rates than the rest of the types. In addition, unemployment rates of type $1 \mathrm{~s}$ are lower than those of type $2 \mathrm{~s}$ and $3 \mathrm{~s}$.

Table 3 lists the proportion of each type by nationality over duration of residence. At the time of their arrival to Germany, there is a higher fraction of type 1s and type 4s among EU immigrants whereas the fraction of type $2 \mathrm{~s}$ and type $3 \mathrm{~s}$ are higher for non-EU immigrants. As can also be seen from the table, the fraction of type $4 \mathrm{~s}$ in the immigrant pool decreases quickly over time due to their high hazard rates. On the contrary, the fraction of type 3s increases over time. The change in the fractions of type $1 \mathrm{~s}$ and $2 \mathrm{~s}$ over time is non-monotonic: their fractions at first increase, then decrease.

This change in the proportion of types over time explains how we can reconcile the increasing hazard functions by type in Figure 4 with the actual hazard functions in Figure 3 , where hazard rates exhibit substantial declining periods. As the returner types (types 1, 2, and 4) leave Germany for their home countries, the fraction of the stayer type (type 3) in the immigrant population increases. As a result, the aggregate hazard rate falls despite increasing hazard rates over time by type.

\subsection{Model Fit}

Here, I illustrate and discuss how the model's predictions as to the return migration and saving choices as well as the exogenous transitions compare to the corresponding values in the data. Chi-squared test statistics are also provided to assess the goodness of fit. Overall, the model does quite well in accounting for these features in the data.

Figure 5 compares the actual and predicted hazard functions according to EU status. The model does a very good job in capturing both the level and timing of return migration for both EU groups despite the marked differences between them. The model's predictions for non-EU immigrants in the few early periods are somewhat above the actual values; however, this is due to sparsity of data in these periods. Further evidence for the model fit of hazard rates is given Table 4, where actual and predicted hazard rates by duration of residence and EU status as well as chi-squared test statistics for goodness of fit are provided. The equality of actual and predicted values is not rejected, at the five percent significant level, except for 
only one period out of eighteen periods for each EU group.

Figure 6 displays how the predicted saving profile compares to the actual saving profile by EU status. For non-EU immigrants, the model captures the downward sloping saving profile as well as the level of saving very well. The only exceptions are the first and last few periods where the observations are fewer. The model also predicts the flat shape of the saving profile of EU immigrants around 9,000 DM very well. Moreover, it captures the decline toward the last few periods.

Next, I present evidence on model fit for the exogenous covariates. Figure 7 illustrates the fit for mean income profile according to EU status. For both groups, the model predicts the level and shape of the income profile very well. Table 5 displays the actual and predicted values of unemployment rate by duration of residence and EU status as well as chi-squared tests for goodness of fit. For both EU groups, the predictions match the data reasonably well. The equality of actual and predicted values can not be rejected, at the five percent statistical significance level, except for three periods for non-EU immigrants and two periods for EU immigrants out of nineteen periods for each. The model fit for the fraction of retired workers by age and EU status along with chi-squared tests for goodness of fit are shown in Table 6. The model does a very good job in capturing the fraction of retired workers by age for both EU groups. Chi-squared tests for the equality of actual and predicted values are not rejected at the five percent statistical significance level at any period.

\subsection{Out-of-Sample Validation}

\subsubsection{Replicating the 1983 Policy for Encouraging Return}

I compare the results of the 1983 policy of cash bonuses conditional on return implemented by the German government with the predicted results of enforcing this policy in my model. According to this policy, 10,500 DM was given to unemployed workers conditional on return, along with an additional 1,500 DM for each child. It is not possible to estimate the actual impact of this policy by examining the rise in the total number of returners during the policy years over the previous ones because another policy was implemented simultaneously, in which immigrants could take back their own contributions (but not the employers' contributions) to the PI system conditional on return.

According to an official report of the German Federal Employment Agency (1985), who oversaw the bonus policy, 38,000 total family members returned by January 1985 using this 
policy. This report also states that 90 percent of these returners were Turks, putting the number of Turks returning as a result of this policy approximately at 34,000. The German Federal Statistics Office reports that 155,336 Turks returned in 1979-80 and 143,059 Turks returned in 1981-82. Assuming that roughly 150,000 Turks would also return in the 1983-84 period in the absence of the policy and that 34,000 Turks who returned using the bonus policy would not have returned in these years at the absence of the policy imply that the policy increased the hazard rate of Turkish immigrants by about 22.7 percent in this period. However, this mark at 22.7 percent is certainly an upper bound because some of these 34,000 immigrants would certainly return in these years even in the absence of the policy.

Next, I examine the impact of this policy in my model. First, I find the effect of the policy at all values of duration of residence; then, I weight these effects according to the duration of residence distribution of Turks in Germany in 1984. When I give Turkish immigrants a 16,000 DM bonus (12,000 DM in 1984 prices) assuming one child per immigrant, I calculate the impact of the policy on the hazard rate as 14.3 percent. When I estimate the impact with a 18,000 DM bonus assuming two children per immigrant, the resulting change is 16.8 percent. Given that the upper bound for the actual impact is about 22.7 percent, the model provides a reasonable match to the actual impact of the policy.

\subsubsection{Other External Validation}

I was not able to validate the saving predictions of my model in the first five periods as there is no saving information in GSOEP for these periods. Paine (1974), based on a report by the State Planning Organization of Turkey in 1971-when all Turkish guestworkers would be in Germany for less then ten years and most for less than four years-, reports a saving rate of 36 percent. Based on a study conducted by the Central Bank of Turkey in 1986, which gathered saving and income information according to immigrants' duration of residence, I calculate that the saving rate of Turkish immigrants with less than four years of residence was 39 percent. The model predicts a saving rate of 36.7 percent in the first two years of residence and a 32.1 percent saving rate during the subsequent two years for Turkish immigrants. Therefore, the model can account for the high saving rate in the early years after arrival, for at least one immigrant group by country of origin.

As shown in Section 6.1, unobserved heterogeneity plays an important role in explaining the observed return migration behavior. A key feature of the distribution of unobserved types was that EU immigrants include a much larger share of type 4s, who have lower labor market 
ability. Referring to German government sources, Paine (1974, p.82) reports that in 1968when most immigrants would be relatively recent arrivals- the proportion of skilled workers among Turkish immigrants was higher than that for other labor exporting countries except for Yugoslavia. Moreover, she adds that the proportion of skilled among the new Turkish migrants arriving after 1968 was also higher than that for other Mediterranean emigration countries. Paine (1974, p.79) also draws attention to the low illiteracy rate among Turkish and Yugoslavian immigrants compared to other nationalities. These facts are consistent with my finding that Turkish and ex-Yugoslavian immigrants contain a much smaller share of immigrant type with lower labor market ability.

\section{The Impact of Immigrants on the German Pension Insurance and Unemployment Insurance Systems}

In this section, I examine the net gains of the German PI and UI systems from immigrants and how return migration influences them. Both PI and UI taxes are levied equally on employees and employers. The total contribution rate of employers and employees as a fraction of employees' gross earnings is 18.7 percent to the PI system and 4.3 percent to the UI system, except for very high gross earnings. (The details on workers' contributions can be seen in Appendix A.) Immigrants can receive their pension benefits even after they return to their home countries. Immigrants who qualify for pension benefits but return before retirement start drawing their benefits at the regular retirement age of 65 . Those who return before the minimum qualification period for pension benefits, it is assumed, take back their own contributions only when they return.

\subsection{Pension Insurance}

The discounted value of net PI contributions of immigrants-including employers' share-at arrival is calculated using the following formula:

$$
P I C=\sum_{s=0}^{t_{r e t}-1} \frac{c \overline{y_{s}}}{(1+r)^{s}}-\sum_{s=t_{r e t}}^{T} \frac{y^{p}}{(1+r)^{s}}-\sum_{s=T+1}^{T+5} \frac{0.6 y^{p}}{(1+r)^{s}}
$$

In (10), $c$ is the total contribution rate of employers and employees, $y^{p}$ is pension income, $t_{r e t}$ is period of retirement. The first term in (10) stands for the contributions, the second term for the receipts of benefits, and the last term for survivor benefits. In Germany, 
survivors receive 60 percent of the benefits of their spouses. In accordance with the life expectancies of immigrants from the five source countries in the sample, I take the life expectancy of females as five years longer than that of males.

The first panel of Figure 8 displays the present value at arrival of the net lifetime contributions of immigrants to the PI system by country of origin and age at entry. PI contributions are positive regardless of age-at-entry and country of origin and quantitatively significant for many groups. Net contributions are higher for early arrivers, especially for non-EU immigrants. For instance, the value of net lifetime contributions of a Turkish immigrant who enters at the age of 18 is 95,076 DM, and that for an ex-Yugoslavian immigrant who enters at the same age is $121,521 \mathrm{DM}$ (1998 prices). Compared to their annual earnings at arrival, net contributions of 18-year-old arrivers are 3.6 times as much for Turkish and 4.2 times as much for ex-Yugoslavian immigrants. For EU immigrants, net contributions are smaller but still important; for 18-year-old arrivers, compared to their annual earnings at arrival they are twice as much for Greek, and 1.6 times as much for Spanish and Italian immigrants. For the oldest arrivers, 48-year-olds, net contributions are still above 20,000 DM for all nationalities, and little variation exists in net contributions across nationalities.

An important factor that contributes to the positive net PI contributions of immigrants is that their average age of retirement is higher than that of natives. The average age of retirement has been rather low in Germany due to the various early retirement possibilities. According to Börsch-Supan and Wilke (2004), the average age of retirement has been below sixty since 1978; it was even below fifty-nine between 1980 and 1985. On the other hand, according to my simulations, the average age of retirement is 61.6 for Turkish, 62.7 for exYugoslavian and Greek immigrants, 63.4 for Italian and Spanish immigrants. The reason to the higher average retirement age of immigrants is that most of the immigrants who return to their home countries can not utilize any of the early retirement schemes.

It is also important to note that a higher average retirement age for all immigrants is possible despite earlier retirement of immigrants who stay in Germany. According to my model, 24.3 percent of 58-year-old and 51.5 percent of 60 -year-old Turks residing in Germany receive pension benefits; whereas, Börsch-Supan and Schnabel (1999) report, based on the 1993-95 waves of the GSOEP, that these percentages are around 20 and 45 for 58-year-old and 60-year-old Germans, respectively. In other words, even though Turkish immigrants who stay in Germany have higher retirement rates conditional on age, when we include those who return to Turkey, their average age of retirement is in fact higher. 
Net contributions of non-EU immigrants are much higher because first non-EU immigrants have shorter lifespans; therefore, they collect less benefits. Second, since EU immigrants are more likely to return, in particular at earlier periods, their contribution period is shorter. A shorter contribution period implies that when the net contribution of each additional year of residence is positive, lifetime contributions will be lower and, in fact, net contributions from staying one more year average positive except for the latest periods for certain groups. (The contribution of each additional year is lower at later periods mainly due to higher unemployment rates.) Finally, EU immigrants include a higher share of the immigrant type with lower labor market ability (type 4) whose net contributions are lower. These facts dominate the effects of a slightly lower retirement age and slightly lower earnings as well as higher rates of unemployment for non-EU immigrants, and their contributions are higher than those of EU immigrants.

Net lifetime PI contributions of younger arrivers are higher for all nationalities, as can be seen in Figure 8. Older arrivers claim benefits for a shorter duration due to their higher average retirement age. However, this fact is overwhelmed by a number of other factors that work in the opposite direction. First, older arrivers have a shorter contribution period due to a shorter remaining worklife. Second, since the earnings of older arrivers are lower, their contribution levels are also lower. (Younger arrivers have both higher earnings at arrival and a longer worklife during which their earnings increase.) Finally, since the fraction of worklife spent as unemployed is higher for older arrivers, their net contributions are lower.

The decline in net contributions by age-at-entry is more pronounced for non-EU immigrants due to the differences between the EU groups in the relationship between age-at-entry and return behavior. While older arrivers among non-EU immigrants are much more likely to return, it is just the opposite for EU immigrants. In addition, the variation across ageat-entry groups among non-EU immigrants is much wider. For instance, among Turkish immigrants, 73 percent of 20-year-old entrants survive in Germany for 20 years whereas only 29 percent of 40-year-old entrants survive for the same duration. On the other hand, the survival rates for 20 years in Germany are 34.5 percent for 20-year-old entrants and 38.4 percent for 40-year-old entrants among Italian immigrants. Since older arrivers of non-EU immigrants have a shorter duration of residence in Germany, they make much lower net contributions than younger arrivers. 


\subsection{Unemployment Insurance}

Net contributions of immigrants to the UI system, which are illustrated in the second column of Figure 8, are positive regardless of age-at-entry for all nationalities but Turks. Even for Turks, net contributions are positive for many of the young-arriver groups. This may be surprising, at first, given the quite high unemployment rates of immigrants from these countries in Germany. The key underlying fact is that high unemployment rates occur late in the life-cycle of these immigrants. As a result, unemployment rates of immigrants currently residing in Germany are very high. However, I calculate the net contributions of all in-migrants to Germany; immigrants who returned made on average much higher net contributions to the UI system because unemployment rates in the early years after arrival were so much lower.

Wide variation exists in net UI contributions across demographic groups; e.g., those of 18-year-old Greek arrivers are 27,104 DM, which is almost equal to their annual earnings at arrival, whereas those of 46-year-old Turkish arrivers average -3,450 DM. The variation across country of origin groups in their net contributions reflects the differences in their unemployment rates. Nonetheless, differences in return migration behavior are also important in explaining the country of origin variation in net contributions. For instance, even though Spanish immigrants are less likely to be unemployed conditional on age compared to Greek immigrants, their net contributions are lower because Spanish immigrants have a lower average duration of residence and, therefore, their per-period net contributions, which are positive until late ages, add up to a lower total amount over their duration of residence.

As can be seen from Figure 8, the age-at-entry profile of net UI contributions is flatter for non-EU immigrants, in particular for Turks. There are two competing effects that bring about this fact. On one hand, older arrivers have higher unemployment rates right after arrival. On the other hand, since unemployment rates increase remarkably over time, when younger arrivers reach the later part of their worklife, their unemployment rates at these ages are higher than those of older arrivers at the same ages. For non-EU immigrants, in particular for Turks, for whom unemployment rates rise more over time, this second effect is much stronger. Therefore, the difference in the likelihood of unemployment at any period during the life-cycle between younger and older arrivers is smaller for non-EU immigrants, which results in a flatter age-at-entry profile for them.

Certain features of return migration behavior also contribute to the flatter age-at-entry profile for non-EU immigrants. As noted before, younger arrivers among non-EU immigrants 
are much less likely to return compared to older ones. In addition, return rates peak later in the hump-shaped hazard function of non-EU immigrants. Therefore, younger arrivers among non-EU immigrants are more likely to stay until later periods when unemployment rates peak. This diminishes the gap in the likelihood of unemployment at any period in Germany between the younger and older arrivers of non-EU immigrants, resulting in a flatter age-at-entry profile.

\section{Counterfactual: Exogenous Return Migration}

The previous studies on the fiscal impact of immigrants treat return migration exogenously. In order to analyze the impact of a such a restriction on immigrants' net contributions to the PI and UI systems, I eliminate the return migration decision in the model and instead take an exogenous hazard function. In this exogenous modeling, hazard rates still vary by duration of residence as well as nationality according to the estimated values in my model.

\subsection{Pension Insurance}

The impact of exogenous return migration on net contributions to the PI system varies substantially across unobserved types. Exogenous return migration decreases the level of return migration for type $4 \mathrm{~s}$ substantially. However, their net contributions do not change much as their per-period contributions average close to zero due to their very high unemployment rates. Many of the type $4 \mathrm{~s}$ who are forced to stay with exogenous return migration are replaced by type 3s (stayer types), who have better labor market outcomes, as actual returners. The resulting increase in the return rates of type $3 \mathrm{~s}$ brings about a fall in their net lifetime contributions for all nationalities because their per-period net contributions are positive. This fall for type $3 \mathrm{~s}$ is especially remarkable for EU immigrants as they become much more likely to return as a result of exogenous return migration.

Exogenous return migration shortens the average duration of residence of type $1 \mathrm{~s}$ and $2 \mathrm{~s}$, in particular that of type 1s, because they are more likely to return at later periods. Since perperiod net contributions are positive for these immigrants, the shorter duration of residence that comes with exogenous return migration decreases their net lifetime contributions. At the same time, there is a countervailing effect: the level of return migration of these types is higher than average; therefore, exogenous return migration brings about a fall in this level, which increases net contributions. For type 1s, for whom the timing effect is especially 
strong, net contributions fall for all nationalities, in particular for EU immigrants who are forced to return much earlier. On the other hand, for type $2 \mathrm{~s}$, the level effect is strong among non-EU immigrants due to the lower return rates imposed by exogenous migration for them. In fact, the level effect dominates for ex-Yugoslavians and their net contributions increase, whereas they fall for all other nationalities, in particular for EU immigrants.

The impact of exogenous return migration on net PI contributions are illustrated in Figure 9 by country of origin and age-at-arrival. For EU immigrants, the replacement of many type $4 \mathrm{~s}$ with type $3 \mathrm{~s}$ as actual returners and the shortened duration of residence of type 1s and 2s dominate, and net contributions decrease for almost all age-at-arrival groups. The fall for certain age-at-arrival groups is especially large; e.g., net contributions fall by more than 40 percent for all Italians who arrive after age 30 . The fall in the net contributions of Italians is larger because first the fall in the duration of residence of type $1 \mathrm{~s}$ and $2 \mathrm{~s}$ is larger as the return rates at earlier periods are the highest for Italians; second they have a higher share of type 3s than other EU groups, most of whom are replaced by type $4 \mathrm{~s}$ as actual stayers. For Turks, the falls in the net contributions of type 2 s and 3 s dominate as they have a higher share of these types, and their contributions fall for all but the oldest age-at-arrival group. The fall in the net contributions of all Turks who arrive before age forty is about 20 percent. Finally, for ex-Yugoslavians, the fall in the net contributions of type 3s dominates, and their net contributions drop for all except for arrivers older than 40 .

Exogenous modeling of return migration behavior also causes rotations on the age-atentry profiles of net PI contributions. The profiles of both non-EU countries rotate counterclockwise; e.g., among ex-Yugoslavians, while net contributions of 22-year-old entrants fall by 17.3 percent, they rise by 9.9 percent for 44 year-old entrants. As noted before, older arrivers among non-EU immigrants are much more likely to return. With exogenous return migration, younger arrivers become more likely to return and older arrivers become more likely to stay. Since per-period net contributions tend to be positive, net contributions of younger arrivers change in a more negative way.

As can also be seen from Figure 9, the change in net contributions is more positive for younger arrivers among EU immigrants; e.g., among Spanish immigrants, while net contributions of 18-year-old entrants increase by 8.7 percent, those of 40-year-old entrants decrease by 27 percent. For EU immigrants, exogenous return migration increases return rates of older arrivers, thereby decreasing their net contributions. However, the differences in return rates across age-at-entry groups are not as pronounced for EU countries as they 
are for non-EU countries. Nonetheless, there is a reinforcing timing explanation. Compared to younger arrivers, older arrivers among EU immigrants are much less likely to return at earlier periods and more likely to return at later periods. Therefore, exogenous return migration makes the hazard function of older arrivers steeper and, therefore, decreases their average duration of residence. Since per-period net contributions are likely to be positive, in particular in earlier periods, the change for older arrivers is more negative.

\subsection{Unemployment Insurance}

As it was for the PI system, the impact of exogenous return migration on net contributions to the UI system varies considerably across unobserved types. The most dramatic change is for type $4 \mathrm{~s}$, who have the highest unemployment rates. Since exogenous return migration increases their average duration of stay, their net contributions fall remarkably for all nationalities. For type 1s, exogenous return migration brings about a substantial drop in duration of residence, especially for EU immigrants. Since type 1s have positive per-period net contributions due to their low unemployment rates, their net lifetime contributions fall for all nationalities, in particular for EU immigrants. Net contributions of type 2s among EU immigrants fall also due to the shortened duration of residence with exogenous return. Net contributions of type $2 \mathrm{~s}$ among non-EU immigrants decrease as well; however, the primary reason in this case is not because they are forced to return earlier, but because they are forced to stay later. The return rates of type $2 \mathrm{~s}$ are high at the periods that unemployment rates peak. However, exogenous return migration forces type $2 \mathrm{~s}$ among non-EU immigrants to stay in Germany at these late periods of high unemployment, which results in a fall in their net contributions. A parallel argument explains why net contributions of type 3s among non-EU immigrants increase with exogenous return. With exogenous return migration, many do not stay until periods of high unemployment that are realized after the peak of the hump of the hazard function and, consequently, their net contributions increase. On the contrary, net contributions of type 3s among EU immigrants fall. Since the return rates of EU immigrants are the highest at very early periods (unlike non-EU immigrants for whom the peak of the hump of the hazard function occurs much later) and since their unemployment rates are not as high as that for non-EU immigrants, exogenous return forces them to return at periods when their per-period contributions still average positive.

The above analysis indicates a fall in net contributions for EU immigrants regardless of type and for all non-EU immigrants except for type 3s. The rise for type $3 \mathrm{~s}$ among non-EU 
immigrants is dominated by the fall for all other types and, consequently, net contributions fall for all nationalities regardless of age at arrival, which is illustrated in Figure 10. In fact, net contributions become negative for all Turkish and Italian immigrants regardless of age-at-arrival and for all ex-Yugoslavian, Greek and Spanish immigrants except for the very young arrivers. Moreover, the magnitude of the fall is substantial for many groups; e.g., net contributions of all Turks arriving after age 30 and all Italians arriving before age 40 fall by more than 25,000 DM, which is almost equivalent to their annual earnings at arrival.

In Figure 10, a prominent feature is the clockwise rotation in the profiles of non-EU countries. While net contributions of 18-year-old Turkish entrants fall by 1,162 DM, those of 40-year-old Turkish entrants fall by 35,231 DM; in fact, net contributions of older arrivers among Turks approach to -40,000 DM. Older arrivers among non-EU immigrants include a much higher share of immigrants with low labor market ability and are much more likely to return compared to younger arrivers. Therefore, exogenous return migration, which decreases the return rates of older arrivers, brings about a remarkable fall in their net contributions.

\section{Policy Experiment: Cash Bonuses Conditional on Return}

This section analyzes the impact of a counterfactual policy experiment in which cash bonuses are provided to unemployed immigrants conditional on return to their home countries. Unemployment rates of immigrants in Germany are very high. These unemployed workers draw significant amount of benefits for extended periods of time. Moreover, they do not pay PI taxes but their unemployment period counts toward the contribution period used in calculating pension benefits. In addition, there is strong persistence in the unemployment state, especially for older working-age immigrants. Therefore, rather than incurring these negative net contributions for extended periods of time, the German government could provide one-time cash bonuses to unemployed immigrants conditional on return.

Table 7 presents the changes in the combined net lifetime contributions to the PI and UI systems per immigrant brought about by various amounts of bonuses given to unemployed workers at various periods in Germany according to nationality and selected values of ageat-arrival. ${ }^{21}$ For EU immigrants, the policy turns out to be totally ineffective in increasing

\footnotetext{
${ }^{21} \mathrm{It}$ is assumed that immigrants do not expect the implementation of such a policy. I experimented with more restrictive policies like targeting the unemployed with longer spells of unemployment. The qualitative
} 
net contributions regardless of age-at-arrival: the changes are either trivial or negative. For non-EU immigrants, the policy is also totally ineffective for young arrivers. As age-at-arrival increases, the impact of the policy becomes stronger; however, this impact is still quite limited for 30-year-old arrivers: even for Turks, for whom the policy matters the most, the rise in net contributions at the periods the policy is the most effective (around the 8th period) is about one percent. Moreover, when the impact of the policy is distributed over various values of duration of residence, the change in net contributions would be rather small even for Turks. The only demographic group for which this policy would have some bite is older arrivers among non-EU immigrants, in particular Turks. The policy increases their net contributions regardless of the period it is implemented and the changes in net contributions are bigger. For instance, the implementation of a 30,000 DM bonus would increase net contributions of 40-year-old Turkish arrivers by more than 1,000 DM as the change in net contributions at all periods is at or above this level. Even a 1,000 DM rise would mean roughly a three percent increase in their net contributions.

The policy is totally ineffective for most demographic groups and only somewhat effective for few demographic groups because first unemployed immigrants are more likely to return anyway, therefore, providing cash bonuses becomes a return gift to many immigrants who would return anyway; second, the change in the duration of residence brought about by the policy is limited. This second point is illustrated in Figure 11, which shows the effect a 50,000 DM bonus given to unemployed immigrants at the eight period in Germany for 30year-old and 40-year-old arrivers among Turkish immigrants. ${ }^{22}$ The policy in fact increases the return rates at the period the bonus is given. However, as can also be seen from the figure, the return rates at the periods immediately following the bonus period decrease. As a result, the duration of residence of unemployed immigrants do not change much.

Figure 11 also explains the relative ineffectiveness of the policy among younger arrivers. The impact of the policy on the hazard rate at the period it is implemented is smaller for 30-year-old arrivers; in addition, the fact that most of these extra-returners are those who would return in the immediately following periods anyway is more apparent for 30-year-old arrivers than 40-year-old arrivers (the gap in the survivor rates closes much faster for 30year-old arrivers). An important reason to the smaller effect of the policy on the hazard results do not change; the quantitative effects are weaker.

${ }^{22}$ Eigth period is chosen because the impact of the policy is the strongest at this period. The reason that a large amount of bonus and Turkish immigrants are chosen is the same. 
rates of younger arrivers is that their unemployment rates are high only at later periods when their accumulated savings are also high.

In order to better understand the ineffectiveness of the policy for most demographic groups, I next examine the impact of the policy by types. The impact of the bonus on net contributions of type 3s (stayer type) is simply none because it does not change their return behavior. The policy makes a very small impact on the return behavior of type 1s because they are much less likely to qualify for the policy due to their lower-than-average unemployment rates and they have a low propensity to return until late ages. On the other hand, the policy makes a stronger impact on type $2 \mathrm{~s}$ and $4 \mathrm{~s}$. The cash bonuses make a stronger impact on the return migration behavior of type $2 \mathrm{~s}$ because accumulated savings matter the most for them in the value of spending the rest of their lives in their home country. The shortened duration of residence for unemployed immigrants increases net contributions of type $2 \mathrm{~s}$. The cash bonuses also make a stronger impact on the return migration of type $4 \mathrm{~s}$ because they are more likely to qualify for the policy due to their very high unemployment rates. However, unlike the case for type $2 \mathrm{~s}$, the impact of the policy on net contributions of type $4 \mathrm{~s}$ is typically negative because since they have a very high likelihood of return anyway, their duration of residence is shortened only slightly with the bonus.

The policy is more effective on non-EU immigrants, in particular for Turks, because first a higher fraction of them qualify for the bonuses due to their higher unemployment rates, second they include a higher share of type $2 \mathrm{~s}$ for whom the change in net contributions is positive whereas EU immigrants include a higher share of type 4s for whom the change in net contributions is more negative.

\section{Conclusions}

In this paper, I investigate the impact of immigrants on the pension and unemployment insurance systems in Germany when return migration is an endogenous choice. For this purpose, I structurally estimate a stochastic dynamic model of joint return migration and saving decisions of immigrants, using a rich longitudinal data set that includes immigrants from five different source countries in Germany. The estimation results indicate that the model can account for the main features of the data very well. In addition, certain out-ofsample predictions of the model yield quite comparable results.

Net contributions of immigrants from the five source countries in this study to the Ger- 
man PI system are positive regardless of age-at-entry. Moreover, the magnitudes of the net contributions are substantial for certain demographic groups; e.g., compared to their annual earnings-at-arrival, net contributions are 3.6 times as much for 18-year-old Turkish arrivers and 4.2 times as much for 18-year-old ex-Yugoslavian arrivers. One key factor that contributes to the positive net contributions to the PI system is the later average age of retirement of immigrants, which arises as a result of the fact that many in-migrants who return to their home country can not take advantage of the various early retirement schemes in Germany. Net contributions to the UI system also average positive regardless of age-at-arrival for all nationalities but Turks for whom net contributions are close to zero. This is surprising given the high unemployment rates of immigrants residing in Germany. The underlying reason to this fact is that immigrants who returned to their home countries were much less likely to be unemployed during their residence in Germany due to low unemployment rates at early years after arrival.

Return migration behavior plays a significant role in determining net contributions of immigrants to the both insurance systems. This is best illustrated in this paper by a counterfactual that treats return migration exogenously-as it has been the practice of the literature so far-while preserving the actual return rates by country of origin and duration of residence. Such exogenous modeling of return migration causes a serious misestimation of net contributions. Net contributions to the PI system fall for almost all demographic groups, and this fall is quite substantial for many groups; e.g., net contributions of all Italians arriving after age 30 fall by more than 40 percent and those of all Turks arriving before age 40 fall by about 20 percent. Net contributions to the UI system also fall for all nationalities regardless of age-at-arrival as a result of exogenous return; in fact, they turn negative for all Turkish and Italian immigrants regardless of age-at-arrival, and for all ex-Yugoslavian, Greek and Spanish immigrants except for the very young arrivers. In addition, the magnitude of the fall is remarkable for many groups; e.g. net contributions of all Turks arriving after age 30 and all Italians arriving before age 40 fall by more than 25,000 DM, which is almost equal to their annual earnings at arrival. The main reason to the underestimation of the net gain of PI and UI systems from immigrants when return migration is treated exogenously is that this ignores the selection in return migration in terms of employment status. In particular, exogenous modeling does not capture the fact that unemployed immigrants are more likely to return and, therefore, seriously underestimates net contributions.

Storesletten (2000) claims that admitting 40-44 year-old immigrants would be the best 
immigration policy in the U.S. according to age-at-entry profiles of net contributions. However, my study shows that not accounting for the heterogeneity in the return migration behavior across age-at-entry groups causes serious rotations in the age-at-entry profiles of net contributions in Germany. For instance, for Spanish immigrants while net PI contributions of 18-year-old entrants increase by 8.7 percent, those of 40-year-old entrants fall by 27 percent; for Turkish immigrants while net UI contributions of 40-year-old entrants fall by $35,231 \mathrm{DM}$, those of 18-year-old entrants decrease by only 1,162 DM. The underlying reason to these rotations is that exogenous return migration does not acknowledge the significant variation in the level and timing of return migration as well as in terms of permanent unobserved characteristics across age-at-entry groups. In particular, the facts that older arrivers among non-EU immigrants include a higher fraction of immigrants with lower labor market ability and display significantly higher return migration rates and that the hazard function of younger arrivers among EU immigrants has a much steeper downward-slope are not accounted for by exogenous return migration.

In order to prevent the burden of unemployed immigrants on the state coffers, some host countries adopted policies to motivate these immigrants to return to their home countries. The results of a counterfactual policy experiment in which cash bonuses are given to unemployed workers conditional on return reveal that such policies are not likely to be effective because first since unemployed immigrants are more likely to return, the bonus becomes a gift to many immigrants who would return anyway; second, even though this policy brings about some additional returners, many of these extra-returners are those who would return in the immediately following periods anyway.

Accounting for return migration as an endogenous choice in studying the fiscal impact of immigration would be quite important in many other countries as well. The empirical literature from various countries reports that emigrants are selected in terms of characteristics like education and earnings ability, which would influence their fiscal impact [see, e.g., Reagan and Olsen (2000) for the U.S.; Lam (1994) for Canada; Jensen and Pedersen (2007) for Denmark; Rooth and Saarela (2007) for Finland and Sweden]. Moreover, the institutional structure of the social security system influences the timing of emigration; e.g., Duleep (1994) reports that there is a rise in the emigration rate right after ten years of residence in the U.S., which is the minimum qualification period for pension benefits. In addition, variation in return migration behavior across age-at-entry groups is also reported in other countries [see, e.g., Reagan and Olsen (2000) for the U.S.; Jensen and Pedersen (2007) for Denmark]. 
Therefore, my finding that examining immigrants' impact on the state coffers while treating return migration exogenously yields results that are significantly off the mark in Germany is likely to carry over to other countries as well.

\section{References}

[1] Auerbach, A.J., J. Gokhale and L. Kotlikoff, "Generational Accounts: A Meaningful Alternative to Deficit Accounting," in D. Bradford, ed., Tax Policy and the Economy, Vol.5. (Cambridge, MA: MIT Press, 1991).

[2] — and P. Oreopoluos, "Analyzing the Fiscal Impact of U.S. Immigration" American Economic Review 89 (1999), 176-80.

[3] Aydemir, A., and C. Robinson, "Global Labor Markets, Return and Onward Migration," Canadian Journal of Economics 41 (2008), 1285-1311.

[4] Berninghaus S., and H.G. Siefer-Vogt, "The Role of the Target Savings Motive in Guest Worker Migration," Journal of Economic Dynamics and Control 17 (1993), 181-205.

[5] Bönin, H., B. Raffelhüschen, and J. Walliser, "Can Immigration Alleviate the Demographic Burden?," FinanzArchiv 57 (2000), 1-21.

[6] Börsch-Supan, A., "Migration, Social Security Systems, and Public Finance," in Siebert Horst, ed., Migration: A Challenge for Europe. (Tübingen, 1994).

[7] —. "A Model under Siege: A Case Study of the German Retirement Insurance System." Economic Journal 110 (2000): F24-45.

[8] —, S. Kohnz, and R. Schnabel, "Micro Modeling of Retirement Decisions in Germany." Social Security Programs and Retirement Around the World: Micro-estimation. NBER Conference Report series. (Chicago and London: University of Chicago Press, 2004).

[9] — and R. Schnabel, "Social Security and Retirement in Germany." Social Security and Retirement Around the World. Ed. Jonathan Gruber and David Wise. (Chicago: The University of Chicago Press, 1999).

[10] — and C. Wilke, "The German Social Security System: How it Was, How it Will Be," NBER Working Paper No. 10525, 2004. 
[11] Borjas, G. J., "The Economics of Immigration," Journal of Economic Literature 32 (1994): 1667-1717.

[12] — and B. Bratsberg, "Who Leaves? The Outmigration of the Foreign-born," Review of Economics and Statistics 78 (1996), 165-176.

[13] Djajic, S., "Migrants in a Guest-Worker System: A Utility Maximizing Approach," Journal of Development Economics 31 (1989), 327-339.

[14] — and R. Milbourne, "A General Equilibrium Model of Guest-worker Migration: A Source-Country Perspective," Journal of International Economics 25 (1988), 335-351.

[15] Dolores-Collado M., I. Iturbe-Ormaetxe, and G. Valera, "Quantifying the Impact of Immigration on the Spanish Welfare State," International Tax and Public Finance 11 (2004), 335-353.

[16] Duleep, H.O., "Social Security and the Emigration of Immigrants," Social Security Bulletin 57 (1994), 37-52.

[17] Dustmann, C., "Return Migration, Uncertainty and Precautionary Savings," Journal of Development Economics 52 (1997), 295-316.

[18] — and O. Kirchkamp, "The Optimal Migration Duration and Activity Choice after Re-migration," Journal of Development Economics 67 (2002), 351-372.

[19] Eckstein, Z., and K.I. Wolpin, "The Specification and Estimation of Dynamic Stochastic Discrete Choice Models: A Survey," Journal of Human Resources 24 (1989), 562-598.

[20] European Health Statistics of the World Health Organization. http://data.euro.who.int/hfadb/.

[21] Freeman, R.B., and R. Oostendorp, "Wages Around the World: Pay Across Occupations and Countries," NBER Working Paper No. 8058, 2000.

[22] German Federal Employment Agency (Bundesagentur für Arbeit), Amtliche Nachrichten der Bundesanstalt für Arbeit (ANBA) Nr. 4/1985.

[23] German Ministry of Finance, "The Tax Policy of the Federal Government", 2004. 
[24] Goeree, J.K., C.A. Holt, and R.P. Thomas, "Risk Averse Behavior in Generalized Matching Pennies Games," Games and Economic Behavior 45 (2003), 97-113.

[25] Harris, J., and M. Todaro, "Migration, Unemployment and Development: A Two-Sector Analysis," American Economic Review 60 (1970), 126-142.

[26] Heckman, J., and B. Singer, "A Method for Minimizing the Impact of Distributional Assumptions in Econometric Models for Duration Data," Econometrica 52 (1984), 271320.

[27] Hill, J.K., "Immigrant Decisions Concerning Duration of Stay and Migration Frequency," Journal of Development Economics 25 (1987), 221-234

[28] Istituto Di Studi E Analisi Economica, Rapporto ISAE, October 2004.

[29] Jasso, G., and M. Rosenzweig, "Estimating the Emigration Rates of Legal Immigrants Using Administrative and Survey Data: The 1971 Cohort of Immigrants to the United States," Demography 19 (1982), 279-290.

[30] Jensen, P., and P.J. Pedersen, "To Stay or Not to Stay? Out-migration of Immigrants from Denmark," International Migration 45 (2007), 87-113.

[31] Keane, M.P., and R.M. Sauer, "A Computationally Practical Simulation Estimation Algorithm for Dynamic Panel Data Models with Unobserved Endogenous State Variables," mimeo., 2003.

[32] — and K.I. Wolpin, "The Career Decisions of Young Men," Journal of Political Economy 105 (1997), 473-522.

[33] — and K.I. Wolpin, "The Effect of Parental Transfers and Borrowing Constraints on Educational Attainment," International Economic Review 42 (2001), 1051-1104.

[34] Kibele E., R. Scholz., V.M. Shkolnikov, "Low migrant mortality in Germany for men aged 65 and older: fact or artifact?," European Journal of Epidemiology 23 (2008), 389-393.

[35] Kırdar, M.G., "Labor Market Outcomes, Savings Accumulation, and Return Migration," Labour Economics 16 (2009): 418-428. 
[36] Koç, İ., and I. Onan, "International Migrants' Remittances and Welfare Status of the Left-Behind Families in Turkey," International Migration Review 38 (2004), 78-112.

[37] Kumcu, E.M., "The Savings Behavior of Migrant Workers: Turkish Workers in W. Germany," Journal of Development Economics 30 (1989), 273-286.

[38] Lam, K., "Outmigration of Foreign-Born Members in Canada," Canadian Journal of Economics 27 (1994), 352-370.

[39] Lee, R., and T. Miller, "Immigration, Social Security, and Broader Fiscal Impacts," American Economic Review 90 (2000), 350-354.

[40] Mayr, K., "The Fiscal Impact of Immigrants in Austria - A Generational Accounting Analysis," Empirica 32 (2005), 181-216.

[41] McLean P.E., and M. Kousis, "Returning Migrant Characteristics and Labor Market Demand in Greece," International Migration Review 20 (1986), 672-675.

[42] Organization for Economic Development and Cooperation (OECD), OECD Indicators, Benefits and Wages, 2002.

[43] Organization for Economic Development and Cooperation (OECD), OECD Indicators, PPP, 2002.

[44] Paine, S., Exporting Workers: the Turkish Case. (Cambridge: Cambridge, 1974).

[45] Razum, O., H. Zeeb, S. Akgün, and S. Yılmaz, "Low overall mortality of Turkish residents in Germany persists and extends into a second generation: merely a healthy migrant effect?," Tropical Medicine and International Health 3 (1998), 297-303.

[46] Reagan, P.B., and R. J. Olsen, "You Can Go Home Again: Evidence from Longitudinal Data," Demography 37 (2000), 339-350.

[47] Rooth D.O., and J. Saarela, "Selection in Migration and Return Migration: Evidence from Micro Data," Economics Letters 94 (2007), 90-95.

[48] Schou, P., "Immigration, Integration and Fiscal Sustainability," Journal of Population Economics 19 (2006), 671-689. 
[49] Sjastaad, L., "The Costs and Returns of Human Migration," Journal of Political Economy 70 (1962), 80-93.

[50] Stark, O., C. Helmenstein, and Y. Yegorov, "Migrants' Savings, Purchasing Power Parity, and the Optimal Duration of Migration," International Tax and Public Finance 4 (1997), 307-324.

[51] Storesletten, K., "Sustaining Fiscal Policy Through Immigration," Journal of Political Economy 108.2 (2000), 300-23.

[52] —. "Fiscal Implications of Immigration - A Net Present Value Calculation," Scandinavian Journal of Economics 105.3 (2003), 487-506.

[53] Tunalı, İ., "Rationality of Migration," International Economic Review 41 (2000), 893920.

[54] Turkish Statistical Institute, Population and Development Indicators, Population and Demography. http://nkg.die.gov.tr/en/goster.asp?aile=1.

[55] Türkiye Cumhuriyeti Merkez Bankası. Yurt Dışındaki Vatandaşlarımızın Tasarruf Eğilimleri Araştırması. (Ankara, 1986).

[56] U.S. Department of Labor, Bureau of Labor Statistics. International Comparisons of Hourly Compensation Costs for Production Workers in Manufacturing, Supplementary Tables. http://www.bls.gov/fls/prodsupptabletoc.htm.

[57] Yang, D., "Why do Migrants Return to Poor Countries? Evidence from Philippine Migrants' Responses to Exchange Rate Shocks," Review of Economics and Statistics 88 (2006), 715-735. 
TABLE 1: Data on Purchasing Power Parity and Expected Wages in the Source Countries

\begin{tabular}{lccccc}
\hline & Turkey & Yugoslavia & Greece & Italy & Spain \\
\hline Purchasing Power Parity & 2.2 & 2.5 & 1.6 & 1.3 & 1.4 \\
Expected Wage / Expected Wage Turkey & 1.0 & 0.8 & 1.1 & 1.6 & 1.3 \\
\hline
\end{tabular}

Notes: Expected wage ratio is at purchasing power parity. Wages are for the manufacturing sector. Since most of the Italian immigrants are from the southern part of the country, I account for the differences in prices between the South and the North by taking the ppp $10 \%$ higher, wages $10 \%$ lower than the national averages (Source: Istituto Di Studi E Analisi Economica, 2004). Wage data are taken from U.S. Bureau of Labor Statistics webpage and Freeman and Oostendorp (2000), and data on the replacement rates of unemployment benefits from OECD Benefits and Wages Indicators (2002). The source for purchasing power parity data is OECD (2002).

TABLE 2: Descriptive Statistics: Immigrant Characteristics

\begin{tabular}{lccrr}
\hline & Mean & SD & Min & Max \\
\cline { 2 - 5 } Turkish & 0.422 & 0.46 & 0 & 1 \\
ex-Yugoslavian & 0.233 & 0.41 & 0 & 1 \\
Greek & 0.092 & 0.35 & 0 & 1 \\
Italian & 0.198 & 0.40 & 0 & 1 \\
Spanish & 0.056 & 0.35 & 0 & 1 \\
Age at Arrival & & & & \\
$\quad$ All & 27.4 & 6.69 & 18 & 49 \\
$\quad$ Turkish & 28.3 & 6.04 & 18 & 48 \\
$\quad$ ex-Yugoslavian & 27.7 & 6.11 & 18 & 45 \\
$\quad$ Greek & 28.0 & 6.71 & 18 & 49 \\
$\quad$ Italian & 25.0 & 7.30 & 18 & 49 \\
$\quad$ Spanish & 27.4 & 7.01 & 18 & 48 \\
Year of Immigration & & & & \\
$\quad$ All & 1969.6 & 5.11 & 1952 & 1983 \\
$\quad$ Turkish & 1970.5 & 4.02 & 1960 & 1981 \\
$\quad$ ex-Yugoslavian & 1970.0 & 3.64 & 1957 & 1981 \\
$\quad$ Greek & 1968.1 & 5.49 & 1957 & 1982 \\
$\quad$ Italian & 1968.8 & 6.72 & 1952 & 1983 \\
$\quad$ Spanish & 1965.9 & 4.78 & 1958 & 1983 \\
Years of Residence Until Last Survey & & & & \\
$\quad$ All & 22.9 & 8.05 & 1 & 48 \\
$\quad$ Turkish & 21.7 & 7.37 & 3 & 40 \\
$\quad$ ex-Yugoslavian & 23.8 & 7.00 & 5 & 43 \\
$\quad$ Greek & 24.0 & 8.67 & 4 & 43 \\
Italian & 23.3 & 9.85 & 1 & 48 \\
$\quad$ Spanish & 25.1 & 7.04 & 3 & 37 \\
\hline
\end{tabular}

Notes: Sampling weights for 1984 are used. 
TABLE 3: Type Proportions over Duration of Residence

\begin{tabular}{|c|c|c|c|c|c|c|}
\hline period & 0 & 5 & 10 & 15 & 20 & 25 \\
\hline \multicolumn{7}{|c|}{ TURKISH } \\
\hline Type 1 & 0.065 & 0.077 & 0.078 & 0.047 & 0.012 & 0.000 \\
\hline Type 2 & 0.297 & 0.334 & 0.170 & 0.057 & 0.012 & 0.000 \\
\hline Туре 3 & 0.415 & 0.542 & 0.745 & 0.895 & 0.976 & 1.000 \\
\hline Type 4 & 0.223 & 0.048 & 0.007 & 0.001 & 0.000 & 0.000 \\
\hline \multicolumn{7}{|c|}{ ex-YUGOSLAVIAN } \\
\hline Type 1 & 0.048 & 0.052 & 0.051 & 0.032 & 0.010 & 0.000 \\
\hline Type 2 & 0.272 & 0.262 & 0.148 & 0.078 & 0.030 & 0.000 \\
\hline Type 3 & 0.549 & 0.640 & 0.790 & 0.889 & 0.959 & 1.000 \\
\hline Type 4 & 0.132 & 0.046 & 0.011 & 0.002 & 0.000 & 0.000 \\
\hline \multicolumn{7}{|l|}{$\overline{G R E E K}$} \\
\hline Type 1 & 0.384 & 0.563 & 0.662 & 0.650 & 0.477 & 0.023 \\
\hline Type 2 & 0.162 & 0.227 & 0.149 & 0.087 & 0.057 & 0.000 \\
\hline Type 3 & 0.082 & 0.129 & 0.174 & 0.261 & 0.466 & 0.977 \\
\hline Type 4 & 0.371 & 0.081 & 0.015 & 0.003 & 0.001 & 0.000 \\
\hline \multicolumn{7}{|c|}{ ITALIAN } \\
\hline Type 1 & 0.174 & 0.362 & 0.383 & 0.327 & 0.226 & 0.004 \\
\hline Type 2 & 0.056 & 0.117 & 0.083 & 0.034 & 0.020 & 0.000 \\
\hline Туре 3 & 0.189 & 0.430 & 0.524 & 0.637 & 0.754 & 0.996 \\
\hline Type 4 & 0.581 & 0.092 & 0.011 & 0.002 & 0.000 & 0.000 \\
\hline \multicolumn{7}{|c|}{ SPANISH } \\
\hline Type 1 & 0.203 & 0.436 & 0.569 & 0.581 & 0.407 & 0.027 \\
\hline Type 2 & 0.127 & 0.262 & 0.186 & 0.111 & 0.068 & 0.000 \\
\hline Type 3 & 0.061 & 0.140 & 0.213 & 0.301 & 0.525 & 0.973 \\
\hline Type 4 & 0.609 & 0.162 & 0.032 & 0.007 & 0.001 & 0.000 \\
\hline
\end{tabular}


TABLE 4: Fit of Hazard Rates by Duration of Residence and EU Status

\begin{tabular}{|c|c|c|c|c|c|c|c|}
\hline \multicolumn{4}{|c|}{ Non-EU Immigrants } & \multicolumn{4}{|c|}{ EU Immigrants } \\
\hline$\overline{\text { Period }}$ & $\overline{\text { Actual }}$ & Predicted & Chi2 & $\overline{\text { Period }}$ & $\overline{\text { Actual }}$ & Predicted & Chi2 \\
\hline 2 & 0.000 & 0.047 & 0.54 & 2 & 0.195 & 0.161 & 0.11 \\
\hline 3 & 0.027 & 0.041 & 0.12 & 3 & 0.114 & 0.119 & 0.01 \\
\hline 4 & 0.020 & 0.039 & 0.25 & 4 & 0.057 & 0.084 & 0.30 \\
\hline 5 & 0.040 & 0.043 & 0.01 & 5 & 0.025 & 0.068 & 1.23 \\
\hline 6 & 0.064 & 0.048 & 0.87 & 6 & 0.055 & 0.054 & 0.00 \\
\hline 7 & 0.042 & 0.055 & 0.89 & 7 & 0.040 & 0.050 & 0.28 \\
\hline 8 & 0.075 & 0.055 & 2.90 & 8 & 0.151 & 0.050 & 39.21 \\
\hline 9 & 0.053 & 0.057 & 0.10 & 9 & 0.049 & 0.053 & 0.05 \\
\hline 10 & 0.034 & 0.049 & 1.73 & 10 & 0.034 & 0.053 & 1.64 \\
\hline 11 & 0.064 & 0.045 & 2.69 & 11 & 0.048 & 0.052 & 0.06 \\
\hline 12 & 0.054 & 0.042 & 1.05 & 12 & 0.045 & 0.058 & 0.84 \\
\hline 13 & 0.007 & 0.032 & 5.08 & 13 & 0.061 & 0.060 & 0.01 \\
\hline 14 & 0.025 & 0.030 & 0.13 & 14 & 0.047 & 0.054 & 0.21 \\
\hline 15 & 0.019 & 0.027 & 0.23 & 15 & 0.087 & 0.064 & 1.35 \\
\hline 16 & 0.051 & 0.025 & 1.49 & 16 & 0.031 & 0.066 & 2.44 \\
\hline 17 & 0.000 & 0.020 & 0.65 & 17 & 0.085 & 0.059 & 1.02 \\
\hline 18 & 0.038 & 0.020 & 0.24 & 18 & 0.129 & 0.067 & 3.00 \\
\hline 19 & 0.000 & 0.023 & 0.14 & 19 & 0.051 & 0.082 & 0.36 \\
\hline
\end{tabular}


TABLE 5: Fit of Unemployment Rates by Duration of Residence and EU Status

\begin{tabular}{|c|c|c|c|c|c|c|c|}
\hline \multicolumn{4}{|c|}{ Non-EU Immigrants } & \multicolumn{4}{|c|}{ EU Immigrants } \\
\hline Period & Actual & Predicted & Chi2 & Period & Actual & Predicted & Chi2 \\
\hline 0 & 0.022 & 0.008 & 11.73 & 0 & 0.017 & 0.004 & 20.96 \\
\hline 1 & 0.019 & 0.011 & 3.04 & 1 & 0.001 & 0.006 & 2.37 \\
\hline 2 & 0.016 & 0.015 & 0.02 & 2 & 0.003 & 0.008 & 1.28 \\
\hline 3 & 0.006 & 0.021 & 5.50 & 3 & 0.002 & 0.012 & 3.60 \\
\hline 4 & 0.005 & 0.026 & 8.71 & 4 & 0.003 & 0.012 & 3.15 \\
\hline 5 & 0.020 & 0.030 & 1.63 & 5 & 0.008 & 0.013 & 0.86 \\
\hline 6 & 0.033 & 0.038 & 0.33 & 6 & 0.006 & 0.016 & 3.04 \\
\hline 7 & 0.060 & 0.047 & 1.64 & 7 & 0.004 & 0.021 & 6.26 \\
\hline 8 & 0.080 & 0.059 & 3.30 & 8 & 0.023 & 0.024 & 0.03 \\
\hline 9 & 0.068 & 0.070 & 0.02 & 9 & 0.013 & 0.030 & 3.57 \\
\hline 10 & 0.080 & 0.088 & 0.27 & 10 & 0.026 & 0.037 & 1.20 \\
\hline 11 & 0.124 & 0.105 & 1.06 & 11 & 0.056 & 0.041 & 1.67 \\
\hline 12 & 0.138 & 0.156 & 0.64 & 12 & 0.055 & 0.054 & 0.00 \\
\hline 13 & 0.189 & 0.185 & 0.02 & 13 & 0.094 & 0.072 & 1.58 \\
\hline 14 & 0.303 & 0.236 & 3.68 & 14 & 0.103 & 0.097 & 0.06 \\
\hline 15 & 0.308 & 0.292 & 0.11 & 15 & 0.102 & 0.121 & 0.44 \\
\hline 16 & 0.305 & 0.334 & 0.16 & 16 & 0.157 & 0.158 & 0.00 \\
\hline 17 & 0.345 & 0.403 & 0.40 & 17 & 0.119 & 0.152 & 0.56 \\
\hline 18 & 0.522 & 0.469 & 0.14 & 18 & 0.199 & 0.208 & 0.02 \\
\hline
\end{tabular}

TABLE 6: Fit of Proportion of Retired by Age and EU Status

\begin{tabular}{ccccccccc}
\hline \multicolumn{4}{c}{ Non-EU Immigrants } & & \multicolumn{4}{c}{ EU Immigrants } \\
\hline \hline Age & Actual & Predicted & Chi2 & & Age & Actual & Predicted & Chi2 \\
\hline 40 & 0.008 & 0.004 & 1.74 & & 40 & 0.000 & 0.001 & 0.39 \\
42 & 0.012 & 0.007 & 1.59 & & 42 & 0.001 & 0.002 & 0.27 \\
44 & 0.017 & 0.013 & 0.49 & & 44 & 0.001 & 0.004 & 0.89 \\
46 & 0.033 & 0.022 & 2.27 & & 46 & 0.012 & 0.008 & 0.78 \\
48 & 0.041 & 0.036 & 0.20 & & 48 & 0.020 & 0.015 & 0.55 \\
50 & 0.049 & 0.056 & 0.23 & & 50 & 0.021 & 0.026 & 0.29 \\
52 & 0.051 & 0.082 & 3.01 & & 52 & 0.028 & 0.044 & 1.60 \\
54 & 0.094 & 0.115 & 0.87 & & 54 & 0.042 & 0.069 & 2.63 \\
56 & 0.179 & 0.154 & 0.77 & & 56 & 0.127 & 0.104 & 1.14 \\
58 & 0.230 & 0.201 & 0.66 & & 58 & 0.137 & 0.143 & 0.05 \\
60 & 0.420 & 0.458 & 0.46 & & 60 & 0.312 & 0.288 & 0.33 \\
62 & 0.467 & 0.498 & 0.18 & & 62 & 0.564 & 0.526 & 0.49 \\
64 & 0.589 & 0.618 & 0.11 & & 64 & 0.672 & 0.716 & 0.48 \\
66 & 0.935 & 0.849 & 1.04 & & 66 & 0.894 & 0.956 & 2.94 \\
68 & 0.881 & 0.933 & 0.34 & & 68 & 1.000 & 0.993 & 0.13 \\
\hline
\end{tabular}


TABLE 7: Change in Total PI and UI Net Contributions per Immigrant with Cash Bonuses to the Unemployed (DM, 1998 prices)

\begin{tabular}{|c|c|c|c|c|c|c|c|c|c|c|}
\hline \multirow[b]{2}{*}{ Bonus Amount } & Turkish & Yugoslavi & Greek & Italian & Spanish & Turkish & Yugoslavi & Greek & Italian & Spanish \\
\hline & \multicolumn{5}{|c|}{ Period $=4($ Age $=28)$} & \multicolumn{5}{|c|}{ Period $=8($ Age $=36)$} \\
\hline 20,000 & -21 & -1 & -25 & -26 & -20 & -43 & -9 & -8 & -12 & 20 \\
\hline 30,000 & -26 & 2 & -35 & -39 & -28 & -39 & -18 & -15 & -8 & 19 \\
\hline 40,000 & -21 & 3 & -43 & -53 & -41 & -18 & 7 & -14 & -17 & 8 \\
\hline \multirow[t]{2}{*}{50,000} & -15 & 3 & -52 & -66 & -52 & -22 & 8 & -29 & -26 & -6 \\
\hline & \multicolumn{5}{|c|}{ Period $=12($ Age $=44)$} & \multicolumn{5}{|c|}{ Period $=16($ Age $=52)$} \\
\hline 20,000 & 13 & 5 & -17 & -11 & -2 & -7 & 6 & 9 & -13 & 10 \\
\hline 30,000 & 15 & 15 & 20 & -11 & -2 & 0 & 0 & 0 & 0 & 0 \\
\hline 40,000 & 2 & 9 & 37 & -16 & -10 & 0 & -9 & 32 & -3 & -9 \\
\hline 50,000 & -1 & -4 & 25 & -16 & -15 & 7 & -15 & 31 & -2 & -1 \\
\hline
\end{tabular}

\begin{tabular}{|c|c|c|c|c|c|c|c|c|c|c|}
\hline \multicolumn{11}{|c|}{ Age at Arrival $=30$} \\
\hline \multirow[b]{2}{*}{ Bonus Amount } & Turkish & Yugoslavi & Greek & Italian & Spanish & Turkish & Yugoslavi & Greek & Italian & Spanish \\
\hline & \multicolumn{5}{|c|}{ Period $=2($ Age $=34)$} & \multicolumn{5}{|c|}{ Period $=4($ Age $=38)$} \\
\hline 20,000 & -7 & 13 & -61 & -159 & -63 & 207 & 114 & 44 & -79 & 22 \\
\hline 30,000 & -55 & -4 & -84 & -196 & -91 & 457 & 185 & 40 & -117 & -4 \\
\hline 40,000 & -2 & 24 & -112 & -256 & -124 & 559 & 256 & -2 & -161 & -16 \\
\hline \multirow[t]{2}{*}{50,000} & 3 & 44 & -142 & -303 & -155 & 480 & 335 & 10 & -220 & -41 \\
\hline & \multicolumn{5}{|c|}{ Period $=8($ Age $=46)$} & \multicolumn{5}{|c|}{ Period $=12($ Age $=54)$} \\
\hline 20,000 & 674 & 23 & 28 & 51 & -8 & 142 & 33 & 92 & 20 & 15 \\
\hline 30,000 & 775 & 13 & 26 & 68 & -35 & 274 & 43 & 77 & 29 & -1 \\
\hline 40,000 & 698 & 90 & 51 & 58 & -49 & 239 & 25 & 90 & 30 & -3 \\
\hline 50,000 & 518 & 129 & 77 & 22 & -34 & 172 & 23 & 69 & 18 & -19 \\
\hline \multicolumn{11}{|c|}{ Age at Arrival $=40$} \\
\hline & Turkish & Yugoslavi & Greek & Italian & Spanish & Turkish & Yugoslavi & Greek & Italian & Spanish \\
\hline Bonus Amount & \multicolumn{5}{|c|}{ Period $=2($ Age $=44)$} & \multicolumn{5}{|c|}{ Period=4 $($ Age $=48)$} \\
\hline 20,000 & 51 & -117 & -198 & -520 & -319 & 2,230 & 432 & 0 & -93 & -16 \\
\hline 30,000 & 978 & -44 & -239 & -639 & -366 & 1,993 & 971 & 48 & -123 & -54 \\
\hline 40,000 & 672 & 248 & -270 & -789 & -446 & 1,605 & 1,329 & 109 & -199 & -63 \\
\hline \multirow[t]{2}{*}{50,000} & 287 & 416 & -313 & -908 & -525 & 1,168 & 1,133 & 90 & -328 & -94 \\
\hline & \multicolumn{5}{|c|}{ Period $=6($ Age $=52)$} & \multicolumn{5}{|c|}{ Period $=8($ Age $=56)$} \\
\hline 20,000 & 2,337 & 353 & 47 & 19 & -19 & 1,266 & 78 & 71 & 18 & -5 \\
\hline 30,000 & 2,027 & 637 & 142 & 50 & -26 & 1,032 & 245 & 154 & 50 & -3 \\
\hline 40,000 & 1,606 & 1,031 & 203 & 18 & 3 & 678 & 160 & 129 & 18 & -13 \\
\hline 50,000 & 1,140 & 801 & 124 & -38 & -39 & 297 & -20 & 54 & -42 & -98 \\
\hline
\end{tabular}


FIGURE 1: Fraction Unemployed and Retired by EU Status
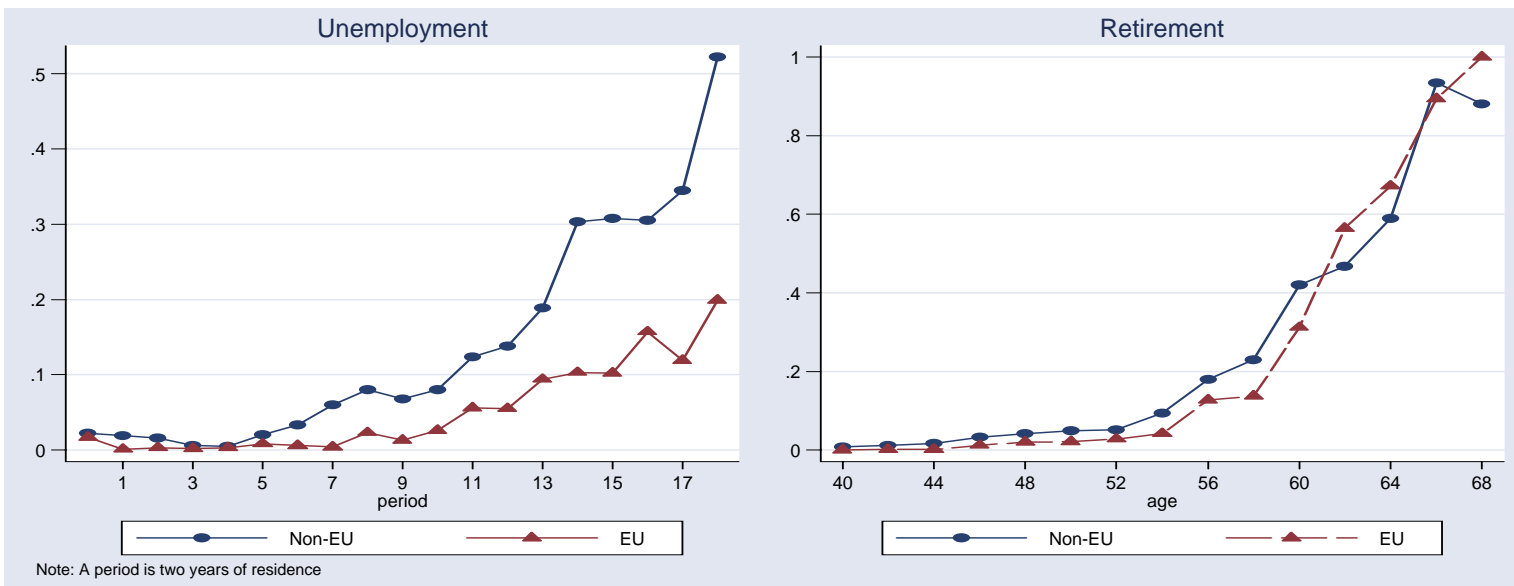

FIGURE 2: Mean Income and Saving Profiles by EU Status (in 1,000DM, 1998 prices)

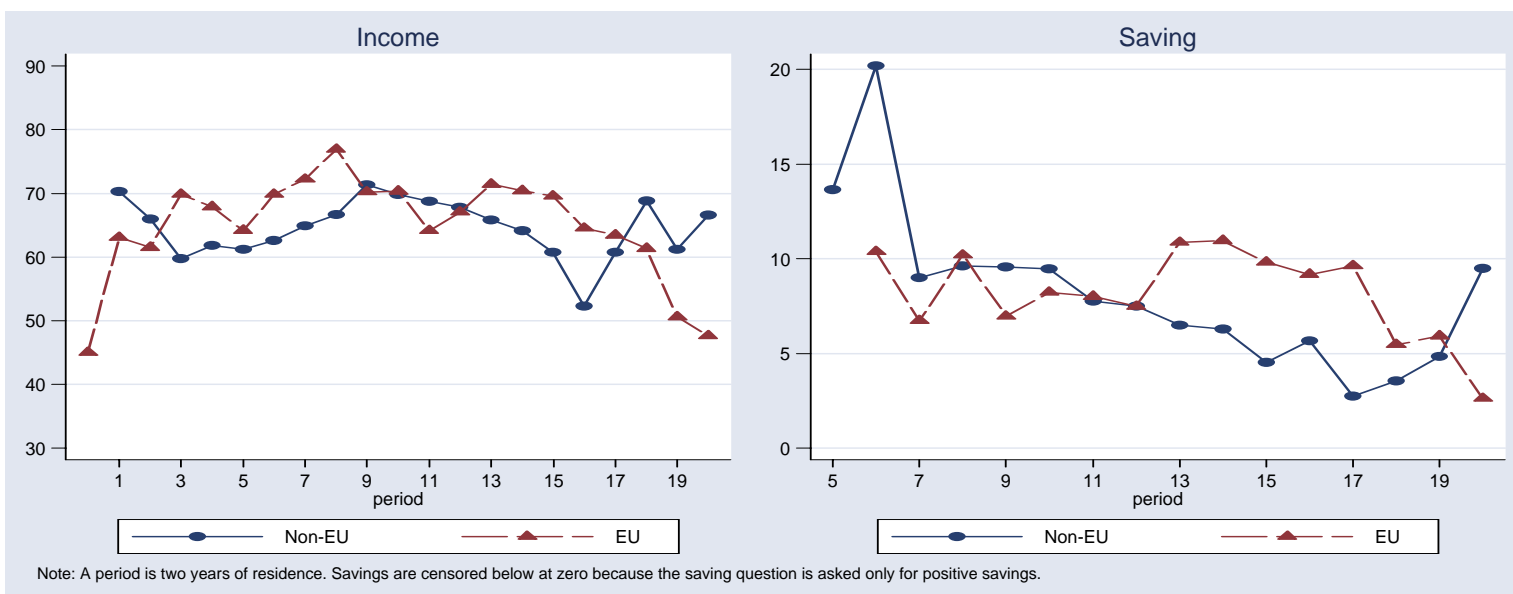

FIGURE 3: Smoothed Hazard Function by EU Status

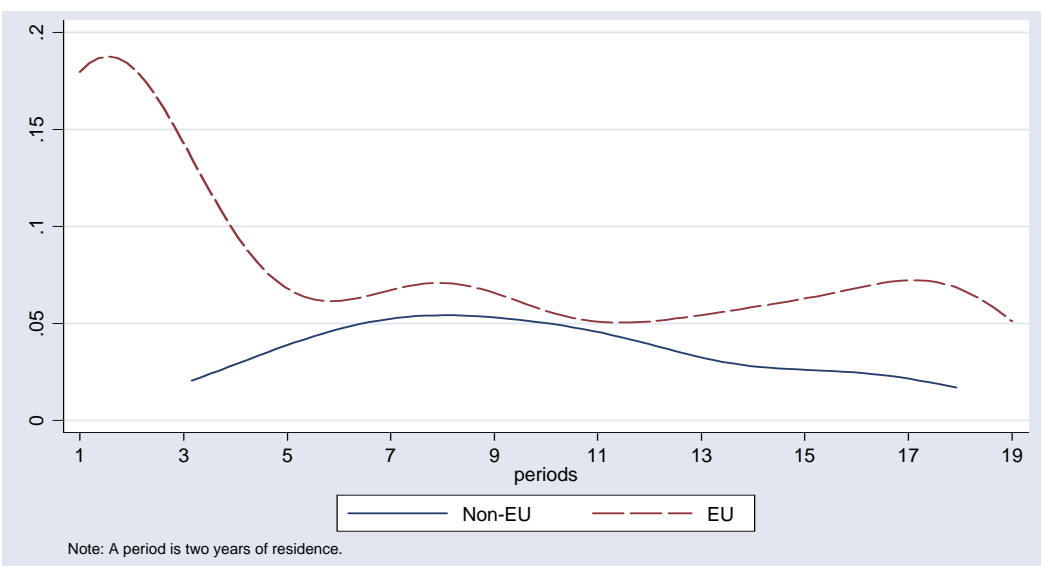


FIGURE 4: Hazard Functions by Unobserved Types: All Immigrants

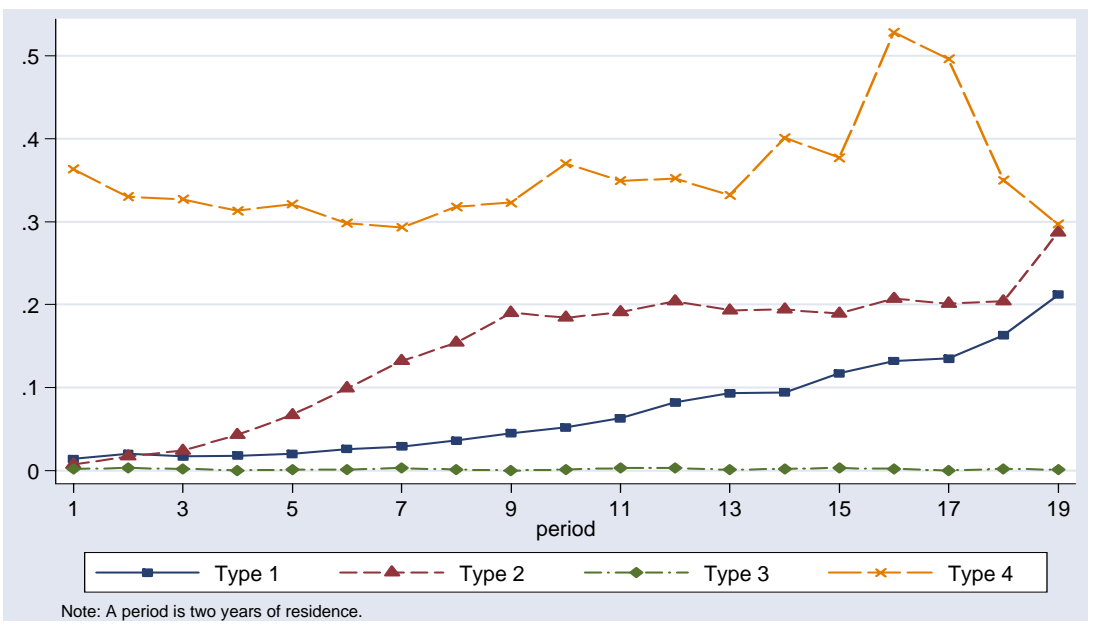

FIGURE 5: Fit of Hazard Functions by EU Status

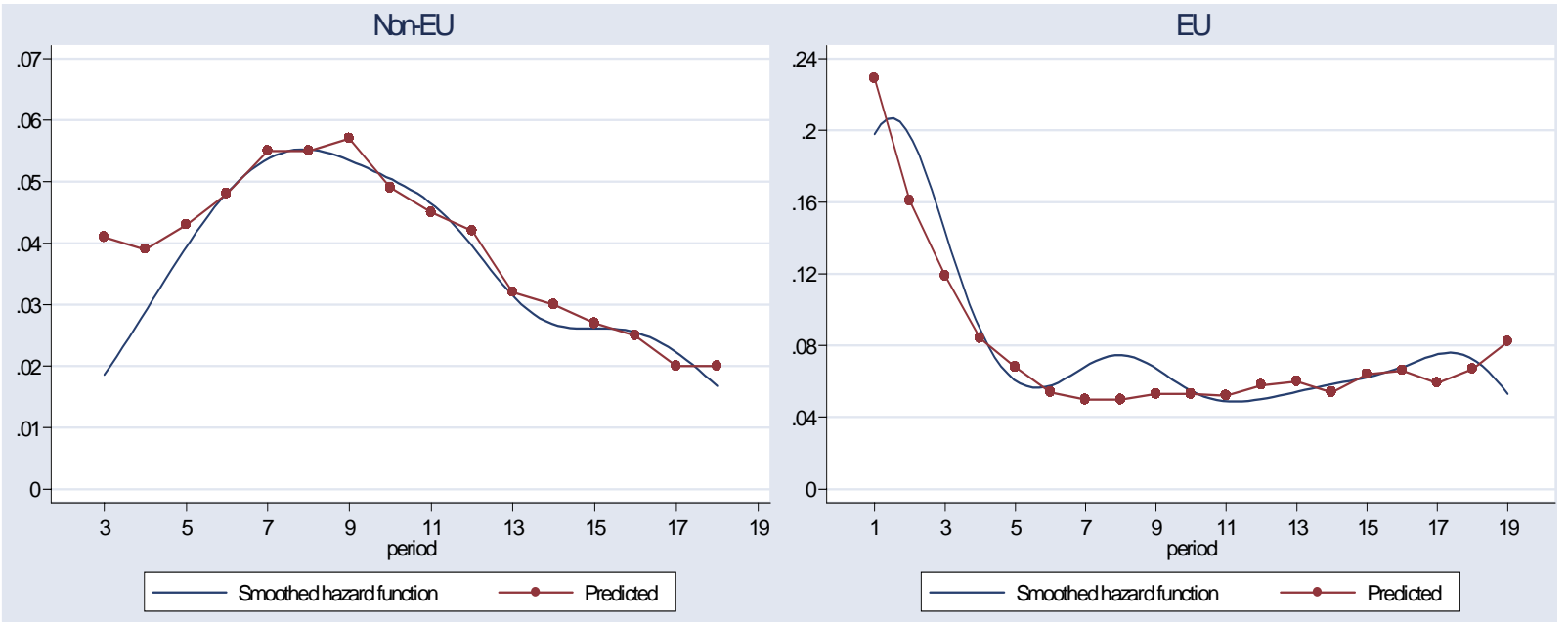


FIGURE 6: Fit of Saving Profiles by EU Status (in 1,000DM, 1998 prices)

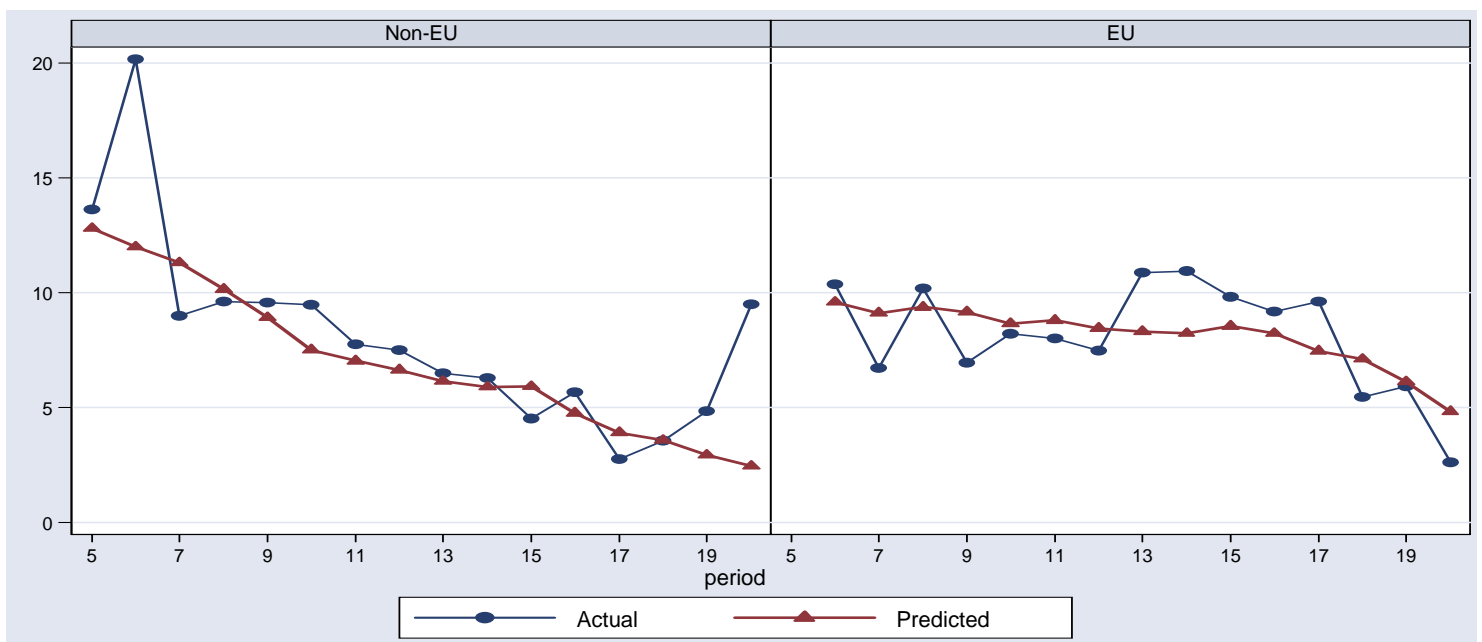

FIGURE 7: Fit of Income Profiles by EU Status (in 1,000DM, 1998 prices)

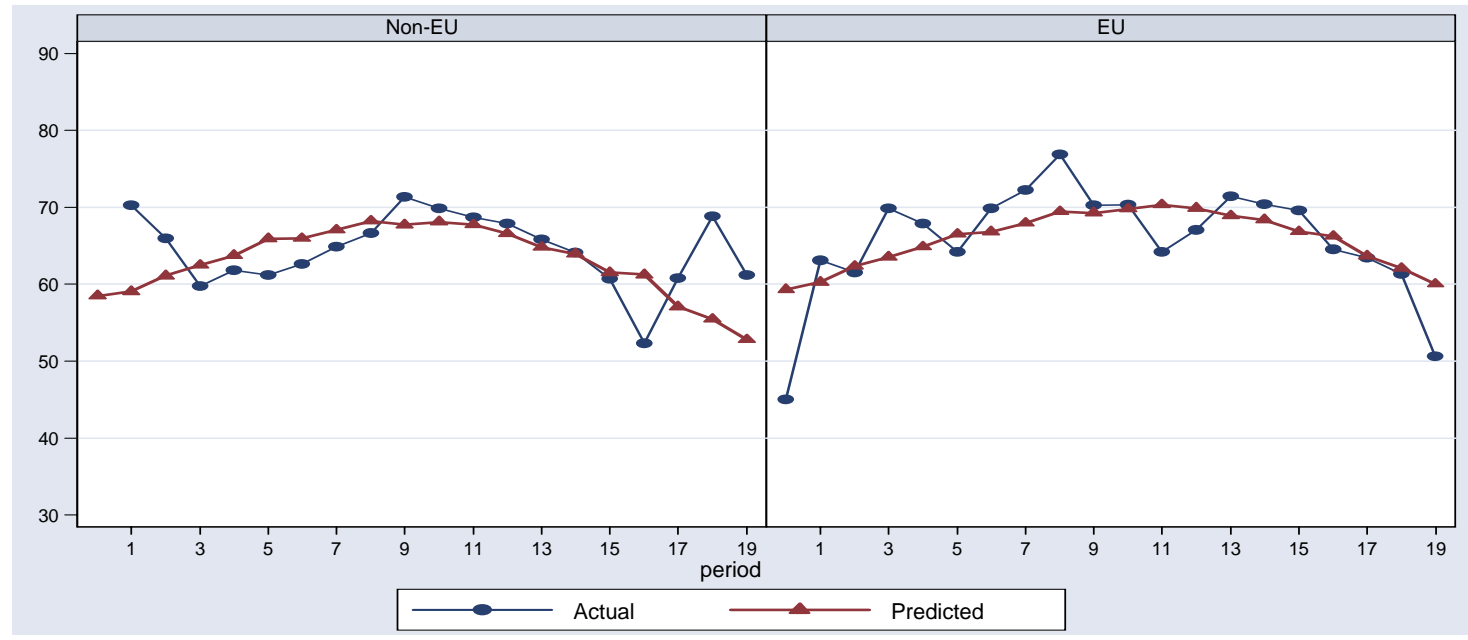


FIGURE 8: Net Lifetime Contributions to Pension Insurance and Unemployment Insurance Systems by Age at Entry and Country of Origin (in 1000DM, 1998 prices)

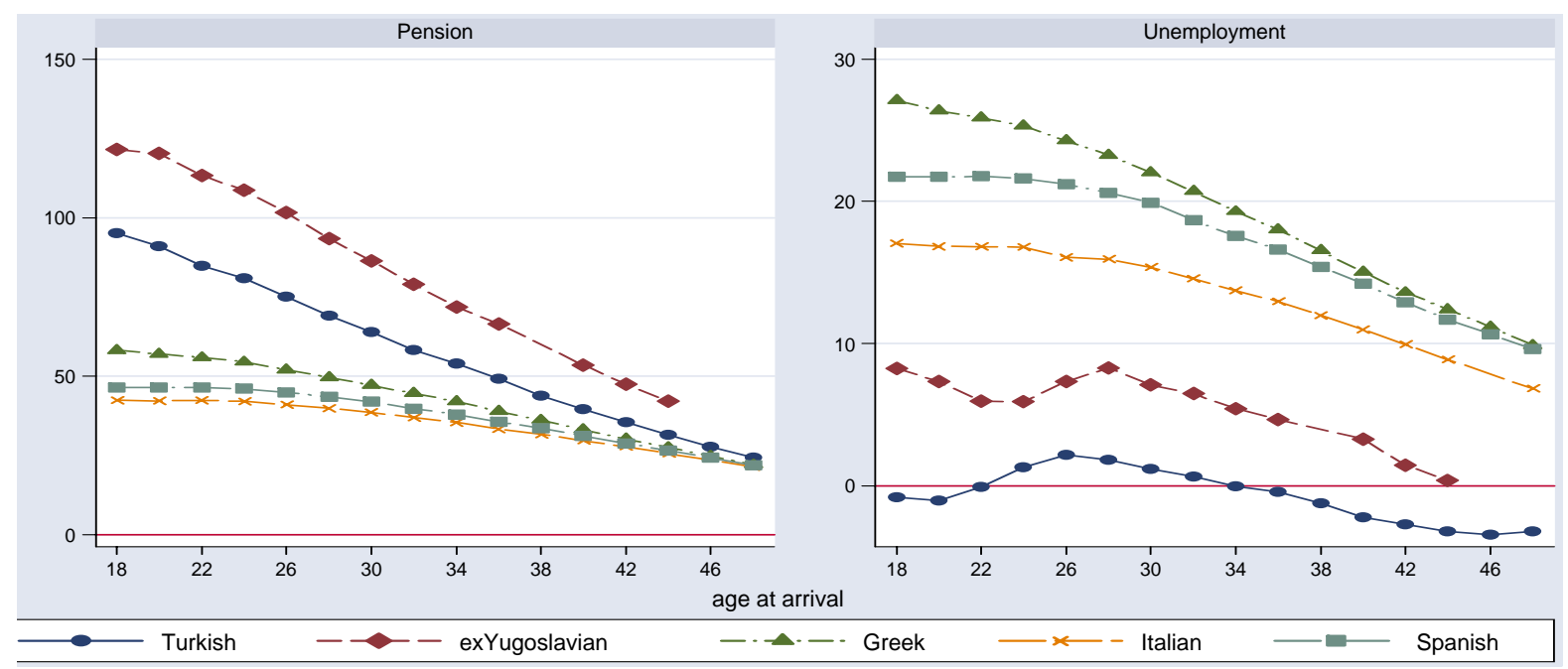

FIGURE 9: Effect of Exogenous Return Migration on Net Pension Insurance Contributions (in 1000DM, 1998 prices)
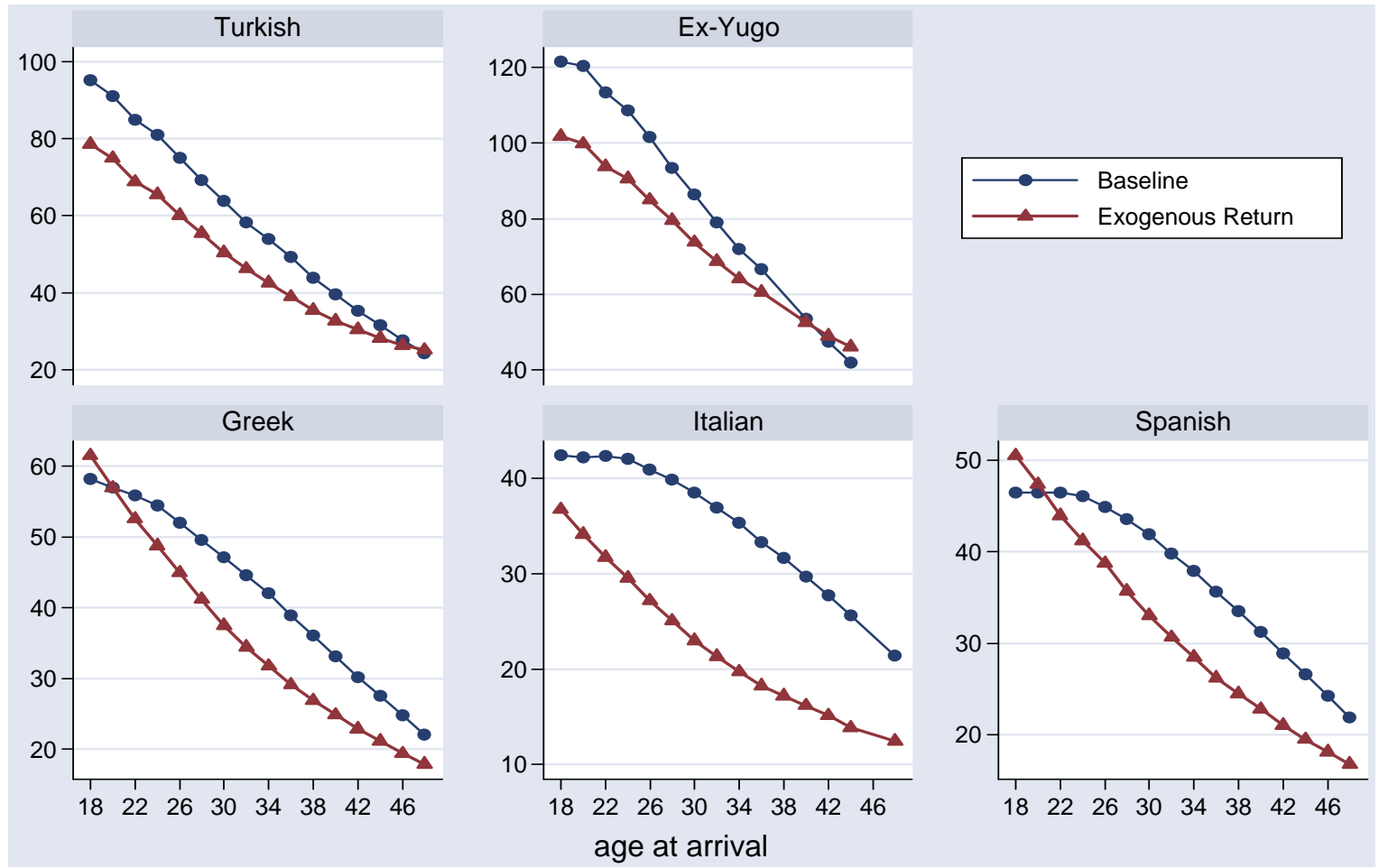
FIGURE 10: Effect of Exogenous Return Migration on Net Unemployment Insurance Contributions (in 1000DM, 1998 prices)

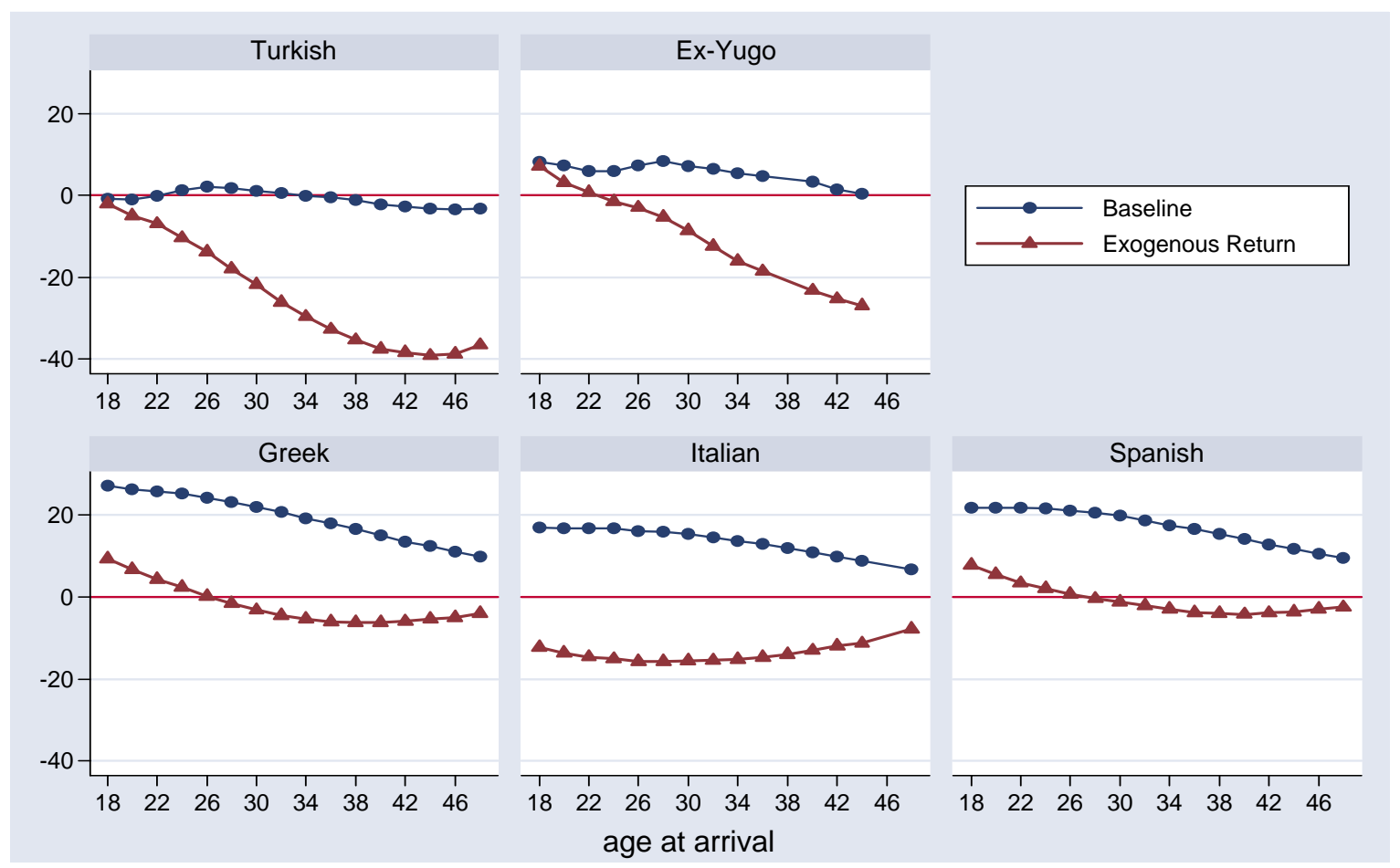

FIGURE 11: Impact of a Cash Bonus Given to the Unemployed on Return Migration Hazard Rates of Turkish Immigrants
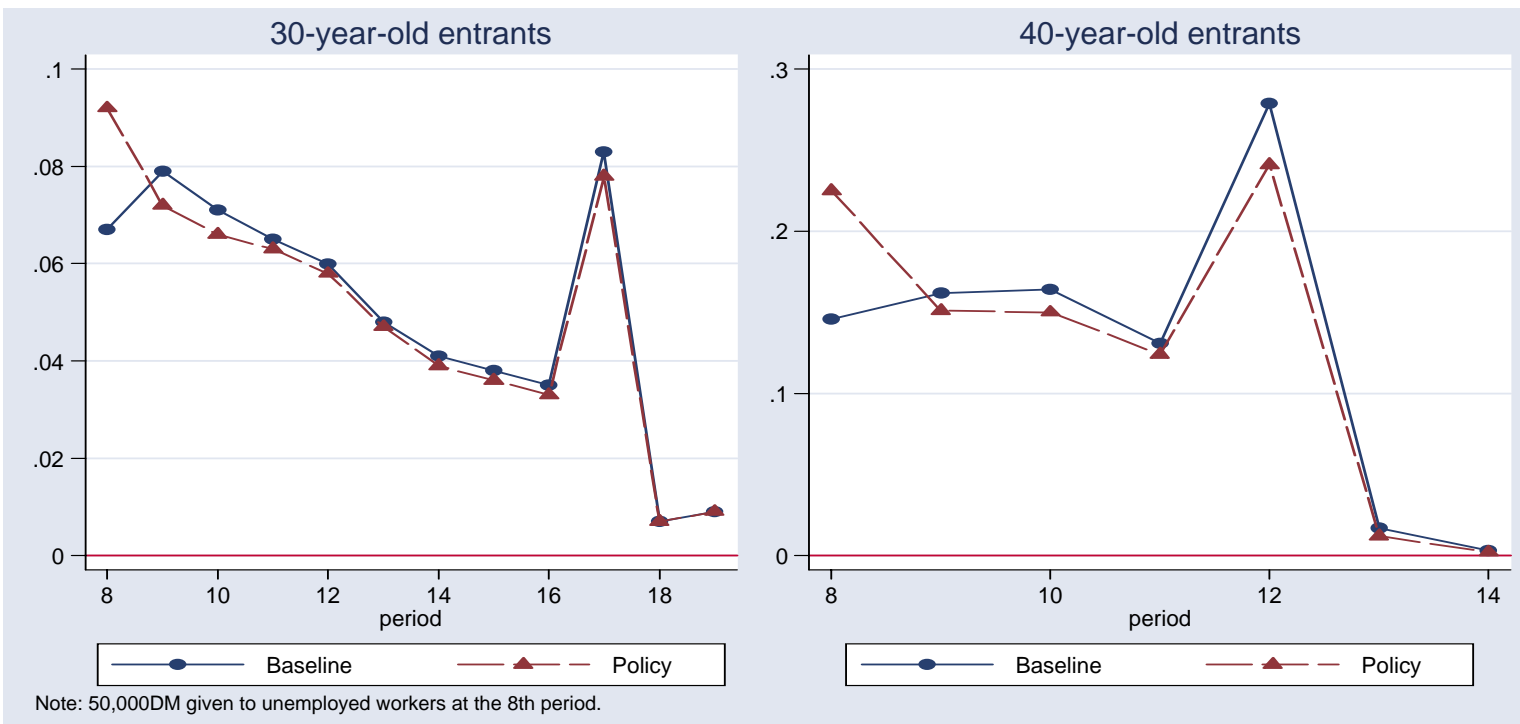


\section{A DETAILS OF LABOR AND TRANSFER INCOME IN GERMANY}

\section{A.1 Labor Income in Germany}

\section{A.1.1 Social Security Contributions}

Pension insurance contribution is applied at a rate of $9.35 \%\left(\tau^{p}\right)$ and unemployment insurance contribution is applied at a rate of $2.15 \%\left(\tau^{u}\right)$, both up to a earnings maximum of $85,000 \mathrm{DM}\left(y^{\max }\right)$ (1998 prices). The health insurance contribution is applied at a rate of $7 \%\left(\tau^{h}\right)$ up to a earnings maximum of $0.75 y^{\max }$. Earnings below 6,000 DM $\left(y^{\mathrm{min}}\right)(1998$ prices $)$ are exempt from social security taxes. Thus, total security taxes, $\Gamma($.$) can be written as follows:$

$$
\Gamma\left(\overline{y_{t}}\right)=\begin{array}{ccc}
0 & \text { if } & \overline{y_{t}} \leq y^{\min } \\
\left(\tau^{p}+\tau^{u}+\tau^{h}\right) \overline{y_{t}} & \text { if } & y^{\min }<\overline{y_{t}} \leq 0.75 y^{\max } \\
\left(\tau^{p}+\tau^{u}\right) \overline{y_{t}}+\tau^{h} y^{\max , 1} & \text { if } & 0.75 y^{\max }<\overline{y_{t}} \leq y^{\max } \\
\left(\tau^{p}+\tau^{u}\right) y^{\max , 2}+\tau^{h} y^{\max , 1} & \text { if } & y^{\max , 2}<\overline{y_{t}}
\end{array}
$$

\section{A.1.2 Net Earnings}

Net earnings, $y_{t}^{\text {net }}$, are gross earnings net of social security contributions and income taxes. In (12), $\tau\left[\overline{y_{t}}-\Gamma\left(\overline{y_{t}}\right)\right]$ is the average income tax rate for $\overline{y_{t}}-\Gamma\left(\overline{y_{t}}\right)$, gross earnings net of social security contributions. $\tau($.) is calculated according to the marginal tax rate schedule in Germany. According to this, income below subsistence income is tax free. Above that level, the marginal tax rate rises from $22 \%$ to $56 \%$ up to an earnings level of 120,000 DM in 1998 prices. (These numbers are chosen to average the values for the years 1965 to 2000-the source is German Ministry of Finance, 2004.) There have been very small changes in the social security contribution and income tax rates over time. I assume that immigrants expect these rates to stay at these levels when they make forecasts about the future in the forward-looking nature of the model.

$$
y_{t}^{n e t}=\left(1-\tau\left[\overline{y_{t}}-\Gamma\left(\overline{y_{t}}\right)\right]\right)\left[\overline{y_{t}}-\Gamma\left(\overline{y_{t}}\right)\right]
$$

\section{A.2 Transfer Income in Germany}

\section{A.2.1 Unemployment Benefits and Unemployment Assistance}

The entitlement duration to unemployment benefits varies from 180 to 960 days depending on the age and experience of the worker. For unemployed workers with at least one child, unemployment benefits are equal to $67 \%$ of their last net earnings whereas unemployment assistance is equal to $57 \%$ of their last net earnings. I make a number of modeling simplifications for tractability. I take unemployment benefits and assistance at any period as the above percentages of expected net earnings at that period rather than the realized last net earnings. In addition, I take the duration of entitlement to unemployment benefits as two years (one decision period). This assumption along with the fact that a period of employment in the model results in 
qualification for benefits in the consecutive period implies that an immigrant who is unemployed this period but was employed last period receives unemployed benefits, whereas an immigrant who has been unemployed for two or more consecutive periods receives unemployment assistance. Finally, I assume that after four years (two periods) of residence all immigrants qualify for unemployment benefits so that last period's labor market status can give us sufficient information on qualification for benefits. (It would be impossible to maintain residence status after 4 years of unemployment for non-EU immigrants. Moreover, many of the guestworkers were already assigned to German employers at the time of entry. Besides, further residence after four years of unemployment would be very unlikely for any economic migrant with zero earnings.) Thus, earnings of an unemployed immigrant can be written as follows:

$$
y_{t}^{u}=\left\{\begin{array}{l}
0 \\
\text { if } \quad\left(l_{t}=\text { unemployed and not qualified for benefits }\right) \\
0.67\left(p H_{t} e^{\sigma_{y}^{2} / 2}-\Gamma\left(p H_{t} e^{\sigma_{y}^{2} / 2}\right)\right)\left[1-\tau\left(p H_{t} e^{\sigma_{y}^{2} / 2}-\Gamma\left(p H_{t} e^{\sigma_{y}^{2} / 2}\right)\right)\right] \\
\text { if } \quad\left(l_{t}=\text { unemployed and } l_{t-1}=\text { employed }\right) \\
0.57\left(p H_{t} e^{\sigma_{y}^{2} / 2}-\Gamma\left(p H_{t} e^{\sigma_{y}^{2} / 2}\right)\right)\left[1-\tau\left(p H_{t} e^{\sigma_{y}^{2} / 2}-\Gamma\left(p H_{t} e^{\sigma_{y}^{2} / 2}\right)\right)\right]-r A_{t} \\
\text { if } \quad\left(l_{t}=\text { unemployed and } l_{t-1}=\text { unemployed and qualified for benefits }\right)
\end{array}\right\}
$$

\section{A.2.2 Pension Benefits}

All three different paths to retirement-regular retirement schemes after age 60, disability, and pre-retirementin fact pay the same level of benefit. In order to qualify for disability benefits, a worker must pass an earnings test. If he passes the stricter earnings test, he is qualified for full benefits. If he can pass only the weaker earnings test, he receives two-thirds of his old-age pension. However, Börsch-Supan and Wilke (2004) report that these rules were interpreted very broadly in the 1970s and the early 1980s, and, as a result, the vast majority of the workers received full benefits. In addition, Börsch-Supan et al. (2002) report that even though pre-retirement income is subject to a negotiation between the worker and the employer, the resulting level generally tracks the public insurance benefits closely.

According to Börsch-Supan and Schnabel (1999), the replacement rate-defined as the ratio of net pension benefits to average net earnings while employed-for a worker with a forty-five year earnings history and average lifetime earnings is 72 percent. In addition, pension benefits are proportional to the duration of contribution. Therefore, for a worker with average lifetime earnings, each additional year of earnings history amounts to a 1.6 percent increase in the replacement rate. (I ignore the adjustment factors for late retirement. Late retirement is very uncommon due to the strong incentives for early-retirement in the German retirement system. Moreover, the importance of these adjustment factors is diminished after accounting for the increase 
in benefits due to the longer years of service life. In addition, the 1992 reform introduced a penalty to the replacement rate in the case of early retirement. The additional penalty is rather small. The pre-1992 replacement rate and that in the model for early retirement decreases due to a shorter service life only.) For tractability, I generalize this property for the worker with average lifetime earnings to all workers. This assumes that the replacement rate does not depend on the relative income level of workers, i.e., there is no redistribution. Börsch-Supan and Schnabel (1999) claim that there is in fact very little redistribution in the German PI system, except for those with very high incomes (those whose incomes are three times as much as the national average). Due to the relatively low income levels of immigrants in Germany, there is a very tiny of fraction of them in this income range.

Again for tractability, in calculating pension benefits at period t, I assume that the replacement rate is applied to the average of expected net earnings at all periods until period $t$ rather than to the average of realized net earnings. When the replacement rate of $0.016 t$ is applied on the average of expected net earnings, the level of pension benefits is found; namely

$$
y_{t}^{p}=0.016 * t * \sum_{j=1}^{t} \frac{\left(p H_{t} e^{\sigma_{y}^{2} / 2}-\Gamma\left(p H_{t} e^{\sigma_{y}^{2} / 2}\right)\right)\left[1-\tau\left(p H_{t} e^{\sigma_{y}^{2} / 2}-\Gamma\left(p H_{t} e^{\sigma_{y}^{2} / 2}\right)\right)\right]}{t}
$$

\section{A.2.3 Social Assistance for Subsistence Income}

Subsistence income for a family depends on its size and varies across states. In 1998, the payment for the head of the household averaged around 520 DM across states. The spouse of the household head receives $80 \%$ of this amount and there is an additional payment for each child, which varies from $50 \%$ to $90 \%$ depending on the age of the child. Since marital status and number of children are strongly correlated with immigrants' age and nationality, I write the subsistence level income, $y_{t}^{\text {subs }}$, as $520 \mathrm{DM}$ times a family multiplier that varies by age and nationality.

\section{B EMPIRICAL SPECIFICATIONS}

\section{B.1 Marginal Utility of Consumption in Germany}

$$
\mu_{t}=\sum_{k=1}^{4} \mu_{k} I(\text { type }=k) \exp \left[\begin{array}{c}
\mu_{5} I\left(a g e_{t} \leq 24\right)+\mu_{6} I\left(a g e_{t} \leq 30\right)+ \\
\mu_{7} I\left(a g e_{t} \geq 50\right)+\mu_{8} I\left(a g e_{t} \geq 60\right)+\mu_{9} I\left(a g e_{t} \geq 70\right)
\end{array}\right]
$$

\section{B.2 Psychic Costs in Germany}

$$
\rho_{t}=\sum_{k=1}^{4}\left(1+\rho_{0} a g e_{0}\right) \rho_{k} I(\text { type }=k)+\rho_{4+k} I(\text { type }=k) t
$$




\section{B.3 Labor Market Status}

$$
\begin{aligned}
& P(l=j)=\left[\begin{array}{c}
\exp \left(\left(\gamma_{17(j-1)+1}+\gamma_{17(j-1)+2} a g e_{0}+\gamma_{17(j-1)+3} I\left(l_{t-1}=0\right)+\gamma_{17(j-1)+4} a_{4} e_{t}+\right.\right. \\
\gamma_{17(j-1)+5} a g e_{t}^{2}+\sum_{z=2}^{5} \gamma_{17(j-1)+4+z} I(\text { country }=z)+\sum_{k=2}^{4} \gamma_{17(j-1)+8+k} I(\text { type }=k) \\
+\sum_{t=0}^{3} \gamma_{17(j-1)+13+t} I(\text { age }=60+2 t)+\gamma_{17(j-1)+17} I(\text { age }=62) I(z \geq 3)
\end{array}\right] \\
& {\left[1+\sum_{h=1}^{2}\left[\begin{array}{c}
\exp \left(\left(\gamma_{17(h-1)+1}+\gamma_{17(h-1)+2} a g e_{0}+\gamma_{17(h-1)+3} I\left(l_{t-1}=0\right)\right.\right. \\
+\gamma_{17(h-1)+4} a g e_{t}+\gamma_{17(h-1)+5} a g e_{t}^{2} \\
+\sum_{z=2}^{5} \gamma_{17(h-1)+4+z} I(\text { country }=z)+\sum_{k=2}^{4} \gamma_{17(h-1)+8+k} I(\text { type }=k)+ \\
\sum_{t=0}^{3} \gamma_{17(h-1)+13+t} I(\text { age }=60+2 t)+\gamma_{17(h-1)+17} I(\text { age }=62) I(z \geq 3)
\end{array}\right]\right] j=1,2} \\
& P(l=0)=1-P(l=1)-P(l=2)
\end{aligned}
$$

\section{B.4 Human Capital}

$$
\ln \left(H_{t}\right)=v_{1} t+v_{2} t^{2}+v_{3} a g e_{0}+\sum_{z=2}^{5} v_{2+z} I(\text { country }=z)+\sum_{k=2}^{4} v_{6+k} I(\text { type }=k)
$$

\section{B.5 Type Probability Functions}

$$
\begin{aligned}
\kappa_{k}= & {\left[\operatorname { e x p } \left(\left(\gamma_{7(k-2)+1}+\gamma_{7(k-2)+2} a g e_{0}+\gamma_{7(k-2)+3} a_{g e} I(z \geq 3)+\sum_{z=2}^{5}+\gamma_{7(k-2)+2+z} I(\text { country }=z)\right] /\right.\right.} \\
& {\left[1+\sum_{h=2}^{4}\left[\begin{array}{c}
\exp \left(\left(\gamma_{7(h-2)+1}+\gamma_{7(h-2)+2} a g e_{0}+\gamma_{7(h-2)+3} a g e_{0} I(z \geq 3)+\right.\right. \\
\sum_{z=2}^{5}+\gamma_{7(h-2)+2+z} I(\text { country }=z)
\end{array}\right]\right] \quad k=2,3,4 } \\
\kappa_{1}= & 1-\sum_{h=2}^{4} \kappa_{h}
\end{aligned}
$$

\section{B.6 Distribution of Shocks}

$\boldsymbol{\eta}_{t}=\left(\eta_{t}^{s}, \eta_{t}^{y}\right)$, the vector of contemporaneous shocks to preferences and earnings, has the following joint distribution.

$$
\left(\begin{array}{c}
\eta_{t}^{s} \\
\eta_{t}^{y}
\end{array}\right) \sim N\left(\left(\begin{array}{l}
0 \\
0
\end{array}\right),\left(\begin{array}{cc}
\sigma_{s}^{2} & \cdot \\
\sigma_{s y} & \sigma_{y}^{2}
\end{array}\right)\right)
$$

\section{B.7 Preferences for Living in the Home Country}

The value of spending the remaining lifetime in the home country, given in (22), has four components: A baseline country dummy, the value of accumulated savings in Germany-where savings are interacted with 
purchasing power parity between the source country and Germany-, the value of potential earnings in the home country after return-which shifts according to the ratio of expected wages in source countries-, and the value of German pension benefits-which is adjusted according to the ratios of purchasing power parities.

$$
\begin{aligned}
& V^{L}\left(\widetilde{S}_{t}\right)=\sum_{\text {country }=z} I(z)\left(\frac{1-\delta(\text { type })^{p_{\text {age }}}}{1-\delta(\text { type })}\right) \pi_{0, z}+ \\
& \left.\sum_{\text {country }=z} I(z)\left[I(\text { type }=1)+\sum_{k=2}^{4} \exp \left(\pi_{1, k-1}\right) I(\text { type }=k)\right]\left[\exp \left(\pi_{1,7}\right)+\exp \left(\pi_{1,8}\right) p_{\text {age }_{t}}\right)\right] \\
& \left(1-\exp \left(\left[I(\text { type }=1)+\sum_{k=2}^{4} \exp \left(\pi_{1, k+2}\right) I(\text { type }=k)\right]\left(\pi_{1,9}+\pi_{1,10} p_{\text {age }}\right) \text { ppp }^{z} A_{t}\right)\right) \\
& +\sum_{z(\text { country })=1}^{5} I(z) \max \left\{\left(\frac{\hat{w}^{z}}{\hat{w}^{\text {Turk }}}\right)^{\exp \left(\pi_{2,1}\right)} \pi_{2,2}+\left(\frac{\hat{w}^{z}}{\hat{w}^{\text {Turk }}}\right)^{\exp \left(\pi_{2,3}\right)} \pi_{2,4} \text { age }_{t}, 0\right\} \\
& +\sum_{z(\text { country })=1}^{5} I(z)\left(\frac{p p p^{z}}{{p p p p^{T u r k}}}\right)^{\exp \left(\pi_{3,1}\right)} \Delta_{\text {age }} \exp \left(\pi_{3,2}\right)\left[1-\exp \left(\pi_{3,3}\right) t\right]
\end{aligned}
$$

Next, I give a more detailed explanation of the individual terms in (22).

1st term (Country Dummy): This is the discounted sum of per period country dummies, $\pi_{0, z}$, which measure the general attractiveness of source countries compared to Germany. It would depend on source country characteristics like per capita income level, whether the country has a socialist regime, income inequality, political stability and so forth. This dummy also includes the transportation cost of return, which would vary by country of origin according to its distance from Germany. In addition, it accounts for the institutional difference between the EU and non-EU countries in that non-EU immigrants can not engage in repeat migration to Germany after they make a permanent return to their home countries.

2nd term (Value of Accumulated Savings): The interaction of accumulated savings with ppp enters the value function in an inverse exponential form. Both parameters of the inverse exponential function vary with the remaining lifetime of the migrant, $p_{a g e_{t}}=\left(\right.$ last_age $\left.^{z}-a g e_{t}\right) / 2$. Moreover, both parameters are allowed to vary across the unobserved types.

3rd term (Value of Potential Earnings at Home): The present discounted value of immigrants' utility from their earnings in their home country after return would depend on their age at return as well as the country they return. Both the constant term and the slope of the age variable varies by $\left(\frac{\hat{w}^{z}}{\hat{w}^{T u r k}}\right)$, which is the ratio of the expected wage level in country z to that in Turkey.

4th term (Value of German Pension Benefits): Pension benefits depend on immigrants' duration of residence in an inverse exponential functional form. (Recall that duration of time in the labor market is equal to duration of residence.) ( $\left.\frac{p p p^{z}}{p p p^{T} u r k}\right)$ accounts for the different purchasing power of German pension benefits in different source countries. $\Delta_{\text {age }}$, given in (22), discounts the value of the benefits to the period 
of return decision. (An immigrant can start receiving pension benefits only after age 64.)

$$
\Delta_{a g e}=I\left(a g e_{t} \geq 64\right)\left(\frac{1-\delta^{p_{a g e_{t}}}}{1-\delta}\right)+I(a g e<64) \delta^{\left(64-a g e_{t}\right) / 2}\left(\frac{1-\delta^{p_{a g e_{t}=64}}}{1-\delta}\right)
$$

In equation (22), the variation according to nationality is limited to four sources: $\pi_{0, z}$-the baseline country dummy-, $p p p^{z}$-the purchasing power in the source country compared to Germany-, and $\hat{w}^{z} / \hat{w}^{\text {Turk }}$ - the ratio of expected wages in source countries when the baseline country is taken as Turkey, and is the number of remaining lifetime periods. (Recall that longevity varies by nationality.)

\section{B.8 Bequest Function}

The parameters of the bequest function is a subset of the parameters of the second term of $V^{L}\left(\widetilde{S}_{t}\right)$. It excludes the parameters of the interaction of accumulated savings with the remaining lifetime period.

$$
\begin{aligned}
B(.)= & {\left[I(\text { type }=1)+\sum_{k=2}^{4} \exp \left(\pi_{1, k-1}\right) I(\text { type }=k)\right] \exp \left(\pi_{1,7}\right) } \\
& \left(1-\exp \left(\left[I(\text { type }=1)+\sum_{k=2}^{4} \exp \left(\pi_{1, k+2}\right) I(\text { type }=k)\right] \pi_{1,9} \text { ppp }^{z} A_{t}\right)\right)
\end{aligned}
$$

\section{Details of the ESTimation MEthod}

The classification error parameters and parameters that characterize the distribution of measurement errors are estimated along with the other parameters of the model. The only element of the model that is estimated separately is the family size multiplier used in calculating the subsistence income, which involves nonparametric smoothing of the age profiles of the probability of being married and the mean number of children by nationality and then applying the rules of the social assistance program on these smoothed values.

\section{C.1 Classification Errors}

\section{C.1.1 Unbiased Classification Error in the Labor Market Outcomes}

Classification errors are unbiased when the probability of a particular outcome is the same in the simulations and in the data. Let $l_{i t}^{*}$ denote the observed labor market outcome in the data and $l_{i t}$ denote the true value from the simulations. Following Keane and Wolpin's (2001) methodology, I write the classification errors in the following linear form.

$$
\begin{aligned}
\theta_{1,1}^{l} & =P\left(l_{i t}^{*}=1 \mid l_{i t}=1\right)=\widetilde{E}+(1-\widetilde{E}) \widehat{P}\left(l_{i t}=1\right) \\
\theta_{1, \neq 1}^{l} & \left.=P\left(l_{i t}^{*}=1 \mid l_{i t} \neq 1\right)=(1-\widetilde{E}) \widehat{P}\left(l_{i t}=1\right)\right)
\end{aligned}
$$

where

$$
\widehat{P}\left[l_{i t}=1\right]=\frac{1}{N} \sum_{n=1}^{N} \operatorname{Pr}\left(l_{i n t}=1\right)
$$


$\widetilde{E}$, in $(25)$ and (26), is the parameter measuring the extent of classification error, which is transformed as in (28) in the estimation. E is estimated along with the other parameters of the model.

$$
\widetilde{E}=1 /[1+\exp (E)]
$$

\section{C.1.2 Biased Classification Error in Return Migration}

The classification error in return migration outcomes has two important properties. First, a classification error is possible only when the reported choice is to leave because the fact that a migrant was interviewed does not leave any doubt that he was in fact in Germany. This implies that a classification error can exist only in the last period in the sample. Second, the fact that there may be a classification error only if the observed choice is to leave implies that the classification error is biased. Thus, $P\left(m_{t}^{*}=1\right) \neq P\left(m_{t}=1\right)$. The following expressions, in which $\mathrm{G}$ is the parameter indicating the degree of misreporting, are used.

$$
\begin{aligned}
& \theta_{1,0}^{m}=P\left(m_{t}^{*}=1 \mid m_{t}=0\right)=\left(\frac{e^{F}}{1+e^{F}}\right) \\
& \theta_{0,1}^{m}=P\left(m_{t}^{*}=0 \mid m_{t}=1\right)=0
\end{aligned}
$$

\section{C.2 Measurement Errors}

The measurement error distributions of earnings and saving are independent and serially uncorrelated. They are specified in the following way.

\section{C.2.1 Measurement Error in Earnings}

$$
y_{t}^{o b s}=y_{t}^{s i m} \exp \left(\varepsilon_{t}^{y}\right) \quad \text { where } \varepsilon_{t}^{y \sim} N\left(0, \sigma_{y, m}^{2}\right)
$$

\section{C.2.2 Measurement Error in Savings}

$$
\left(A_{t+1}-A_{t}\right)^{o b s}=\left(A_{t+1}-A_{t}\right)^{s i m}+\varepsilon_{t}^{s} \quad \text { where } \varepsilon_{t}^{s \sim} N\left(0, \sigma_{s, m}^{2}\right)
$$

\section{C.3 Calculation of the Probabilities of Reported Spells Conditional on the Simulated Spells}

The probability of observing the reported spells conditional on the simulated spells can be written as in (33).

$$
\begin{aligned}
& P\left(\left(D_{i}^{o b s}, X_{i}^{\text {obs }}\right) \mid\left(D_{i n}^{\text {sim }}, X_{\text {in }}^{\text {sim }}\right)\right) \\
= & \left.P\left(M_{i}^{\text {obs }} \mid M_{i n}^{\text {sim }}\right) \prod_{t=1}^{T_{i}} \operatorname{Pr}\left(A_{i t}-A_{i t-1}\right)^{\text {obs }} \mid\left(A_{\text {int }}-A_{\text {int }-1}\right)^{\text {sim }}\right] \operatorname{Pr}\left(y_{i t}^{\text {obs }} \mid y_{i n t}^{\text {sim }}\right) \operatorname{Pr}\left(l_{i t}^{\text {obs }} \mid l_{\text {int }}^{\text {sim }}\right)
\end{aligned}
$$




\section{C.3.1 Calculation of $P\left(M_{i}^{\text {obs }} \mid M_{i n}^{\text {sim }}\right)$}

The calculation of the probability of observing the registered migration spell conditional on the true migration spell can be categorized into four groups:

Case 1: The simulated spell ends earlier with an exit.

$\begin{array}{llllll}\text { Data } & 0 & 0 & 0 & 0 & \mathrm{X} \\ \text { Simulated } & 0 & 0 & 0 & 1 & \end{array}$

This has zero probability because since a return took place, this person could not have been in the sample. $P\left(M_{i}^{\text {obs }} \mid M_{i n}^{\text {sim }}\right)=0$.

Case 2: The data and simulated spell both end with an exit at the same period.

$\begin{array}{llllll}\text { Data } & 0 & 0 & 0 & 0 & 1 \\ \text { Simulated } & 0 & 0 & 0 & 0 & 1\end{array}$

There are $T_{1}$ periods of correct reporting of staying in Germany as well as correct reporting of the exit. The probability of correct of reporting of an exit, $\theta_{1,1}^{m}$, is equal to 1 . Thus, $P\left(M_{i}^{\text {obs }} \mid M_{i n}^{\text {sim }}\right)=\left(1-\theta_{1,0}^{m}\right)^{T_{1}}$.

Case 3: The data spell ends earlier with an exit.

$\begin{array}{lllllllll}\text { Data } & 0 & 0 & 0 & 0 & 1 & \cdot & \cdot & \text {. } \\ & & & & \end{array}$

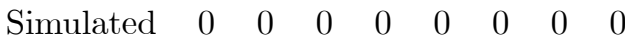

There are $T_{1}$ periods of correct reporting of staying in Germany and $T-T_{1}$ periods of mismatch (classification error). Therefore, $P\left(M_{i}^{\text {obs }} \mid M_{i n}^{\text {sim }}\right)=\left(1-\theta_{1,0}^{m}\right)^{T_{1}}\left(\theta_{1,0}^{m}\right)^{T-T_{1}}$. OR

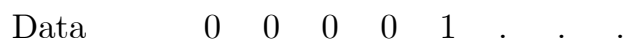

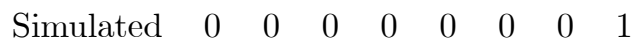

There are $T_{1}$ periods of correct reporting of staying in Germany and $T-T_{1}-1$ periods of mismatch (classification error). Therefore, $P\left(M_{i}^{\text {obs }} \mid M_{i n}^{\text {sim }}\right)=\left(1-\theta_{1,0}^{m}\right)^{T_{1}}\left(\theta_{1,0}^{m}\right)^{T-T_{1}-1}$.

Case 4: The data spell ends earlier without an exit.

$\begin{array}{llllllll}\text { Data } & 0 & 0 & 0 & 0 & 0 & \cdot & \cdot \\ \text { Simulated } & 0 & 0 & 0 & 0 & 0 & 0 & \mathrm{X}\end{array}$

There are $T_{1}$ periods of correct reporting of staying in Germany and $T-T_{1}$ periods of missing information. Thus, $P\left(M_{i}^{o b s} \mid M_{i n}^{s i m}\right)=\left(1-\theta_{1,0}^{m}\right)^{T_{1}}$.

\section{C.3.2 Calculation of $P\left(l_{i}^{o b s} \mid l_{i n}^{s i m}\right)$}

Unlike the above case, a classification error in the reported labor market status can exist at any period. Therefore, the probability of observing the reported labor market status conditional on the simulated outcome can be written as follows. 


$$
\begin{aligned}
& \operatorname{Pr}\left(l_{i t}^{\text {obs }}=1 \mid l_{\text {int }}^{\text {sim }}=1\right)=\theta_{1,1}^{l} \\
& \operatorname{Pr}\left(l_{i t}^{\text {los }}=1 \mid l_{\text {int }}^{\text {sim }} \neq 1\right)=\theta_{1,0}^{l}
\end{aligned}
$$

\section{C.3.3 Calculation of $P\left(\left(A_{t+1}-A_{t}\right)_{i}^{\text {obs }} \mid\left(A_{t+1}-A_{t}\right)_{i n}^{\text {sim }}\right)$}

The saving data in the GSOEP are censored below at zero. (Since I aggregate the data into two year periods, there are censoring values other than zero as well.) For censored observations, the probability that $A_{t+1}-A_{t}$ equals the censoring value is given in (36), where $\Phi$ is the standard normal cumulative distribution function.

$$
P\left(\left(A_{t+1}-A_{t}\right)_{i}^{o b s} \mid\left(A_{t+1}-A_{t}\right)_{i n}^{s i m}\right)=\Phi\left(\frac{\left(A_{t+1}-A_{t}\right)_{i}^{o b s}-\left(A_{t+1}-A_{t}\right)_{i n}^{s i m}}{\sigma_{s, m}}\right)
$$

For uncensored observations, the probability is given in (37), where $\phi$ is the standard normal density.

$$
P\left(\left(A_{t+1}-A_{t}\right)_{i}^{o b s} \mid\left(A_{t+1}-A_{t}\right)_{i n}^{s i m}\right)=\frac{1}{\sigma_{s, m}} \phi\left(\frac{\left(A_{t+1}-A_{t}\right)_{i}^{o b s}-\left(A_{t+1}-A_{t}\right)_{i n}^{s i m}}{\sigma_{s, m}}\right)
$$

C.3.4 Calculation of $P\left(y_{i}^{\text {obs }} \mid y_{i n}^{\text {sim }}\right)$

$$
P\left(y_{i}^{o b s} \mid y_{i n}^{\text {sim }}\right)=\prod_{t=1}^{T_{i}} \frac{1}{\sigma_{y, m}} \phi\left(\frac{y_{i t}^{o b s}-y_{i n t}^{\text {sim }}}{\sigma_{y, m}}\right)
$$

\section{PARAMETER EStimates}

Marginal Utility Parameters

$\begin{array}{ccccccccc}\mu_{1} & \mu_{2} & \mu_{3} & \mu_{4} & \mu_{5} & \mu_{6} & \mu_{7} & \mu_{8} & \mu_{9} \\ 8.217 & 4.539 & 6.003 & 4.189 & -0.361 & -0.146 & -1.929^{b} & -2.324^{b} & -1.929^{b} \\ (0.074) & (0.248) & (0.279) & (0.013) & (0.059) & (0.006) & (0.232) & (0.278) & (0.297)\end{array}$

Psychic Cost Parameters

$\begin{array}{ccccccccc}\rho_{0} & \rho_{1} & \rho_{2} & \rho_{3} & \rho_{4} & \rho_{5} & \rho_{6} & \rho_{7} & \rho_{8} \\ 0.899^{b} & 0.458^{h} & 0.452^{h} & 0.387^{h} & 0.678^{h} & 1.071^{a} & 5.323 & 6.503 & 2.198^{a} \\ (0.032) & (0.017) & (0.010) & (0.256) & (0.011) & (0.293) & (0.093) & (0.001) & (0.167)\end{array}$

Value Home Parameters

$\begin{array}{cccccccccccc}\pi_{0,1} & \pi_{0,2} & \pi_{0,3} & \pi_{0,4} & \pi_{0,5} & \pi_{1,1} & \pi_{1,2} & \pi_{1,3} & \pi_{1,4} & \pi_{1,5} & \pi_{1,6} \\ -2.334^{g} & -3.109^{g} & -0.841^{g} & -0.334^{g} & -0.424^{g} & -0.732 & -0.271 & -0.128 & 2.969 & -0.614 & -0.685 \\ (0.038) & (0.150) & (0.262) & (0.013) & (0.050) & (0.041) & (0.075) & (0.005) & (0.024) & (0.053) & (0.005) \\ \pi_{1,7} & \pi_{1,8} & \pi_{1,9} & \pi_{1,10} & \pi_{2,1} & \pi_{2,2} & \pi_{2,3} & \pi_{2,4} & \pi_{3,1} & \pi_{3,2} & \pi_{3,3} \\ 12.29 & 9.161 & -0.418^{d} & 0.590^{e} & -0.171 & 1.236^{h} & -1.824 & -0.325^{g} & -2.254 & 9.769 & -5.200^{b} \\ (0.031) & (0.135) & (0.012) & (0.065) & (0.097) & (0.063) & (0.090) & (0.008) & (0.181) & (0.017) & (0.110)\end{array}$


Type Probability Function

$\begin{array}{ccccccccccc}\kappa_{1} & \kappa_{2} & \kappa_{3} & \kappa_{4} & \kappa_{5} & \kappa_{6} & \kappa_{7} & \kappa_{8} & \kappa_{9} & \kappa_{10} & \kappa_{11} \\ 1.197 & 2.821^{b} & -2.093^{b} & 2.207^{a} & -2.136 & -2.389 & -1.736 & 2.549 & -7.355^{b} & 8.241^{b} & 5.897^{a} \\ (0.509) & (0.286) & (0.368) & (0.451) & (0.646) & (0.950) & (1.425) & (0.379) & (0.150) & (0.375) & (0.478) \\ \kappa_{12} & \kappa_{13} & \kappa_{14} & \kappa_{15} & \kappa_{16} & \kappa_{17} & \kappa_{18} & \kappa_{19} & \kappa_{20} & \kappa_{21} & \\ -4.186 & -2.536 & -3.846 & 9.702^{a} & 2.288^{b} & -4.803^{b} & -2.125^{a} & -7.600^{a} & 4.109^{a} & 3.601^{a} \\ (0.448) & (0.925) & (0.899) & (0.395) & (0.202) & (0.327) & (0.371) & (0.351) & (0.783) & (0.848)\end{array}$

\section{Labor Market Status}

$\begin{array}{ccccccccc}\gamma_{1} & \gamma_{2} & \gamma_{3} & \gamma_{4} & \gamma_{5} & \gamma_{6} & \gamma_{7} & \gamma_{8} & \gamma_{9} \\ -10.394 & 0.047 & -2.469 & 0.423 & -0.291^{b} & -0.346 & -2.323 & -1.996 & -1.972 \\ (0.039) & (0.001) & (0.108) & (0.002) & (0.001) & (0.118) & (0.149) & (0.152) & (0.189) \\ \gamma_{10} & \gamma_{11} & \gamma_{12} & \gamma_{13} & \gamma_{14} & \gamma_{15} & \gamma_{16} & \gamma_{17} & \gamma_{18} \\ -3.033 & -3.512 & -3.482 & 2.141 & -1.469 & 0.863 & 0.973 & 3.539 & 11.421 \\ (0,072) & (0.087) & (0.076) & (0.132) & (0.043) & (0.134) & (0.110) & (0.168) & (0.023) \\ \gamma_{19} & \gamma_{20} & \gamma_{21} & \gamma_{22} & \gamma_{23} & \gamma_{24} & \gamma_{25} & \gamma_{26} & \gamma_{27} \\ 0.043 & -5.493 & -2.501^{a} & 0.118^{b} & 0.359 & 0.888 & 0.847 & 1.307 & -0.525 \\ (0.001) & (0.035) & (0.007) & (0.001) & (0.028) & (0.100) & (0.023) & (0.036) & (0.089) \\ \gamma_{28} & \gamma_{29} & \gamma_{30} & \gamma_{31} & \gamma_{32} & \gamma_{33} & \gamma_{34} & & \\ -1.699^{a} & -2.541 & 0.629 & 0.493 & -0.388 & -1.120 & -1.201^{a} & & \\ (0.007) & (0.025) & (0.090) & (0.060) & (0.137) & (0.107) & (0.050) & & \end{array}$

\section{Human Capital}

$\begin{array}{cccccccccc}v_{1}^{b} & v_{2}^{c} & v_{3}^{b} & v_{4} & v_{5} & v_{6} & v_{7} & v_{8} & v_{9} & v_{10} \\ 0.182^{a} & -0.907^{d} & -0.333^{b} & 0.716^{a} & 0.626^{a} & -0.228^{a} & 0.992^{a} & -0.195 & -0.155^{a} & 0.254^{a} \\ (0.004) & (0.106) & (0.008) & (0.076) & (0.101) & (0.042) & (0.077) & (0.006) & (0.021) & (0.019)\end{array}$

Classification and Measurement Errors, Transitory Shocks

$\begin{array}{ccccccc}E & F & \sigma_{y, m} & \sigma_{s, m} & \sigma_{y}^{2} & \sigma_{s}^{2} & \sigma_{s y} \\ -1.715 & -6.607 & 0.3086 & 1.060^{h} & 1.3839 & 0.0013 & 0.0096 \\ (0.088) & (0.379) & (0.001) & (0.010) & (0.0071) & (0.0096) & (0.0007)\end{array}$

Discount Rates, Interest Rate, Risk Aversion Parameter, Price of Human Capital

\begin{tabular}{ccccccc}
$\delta_{1}$ & $\delta_{2}$ & $\delta_{3}$ & $\delta_{4}$ & $r$ & $\lambda$ & $p^{e}$ \\
0.9750 & 0.9890 & 0.9806 & 0.9764 & $1.5685^{b, i}$ & 0.6304 & $11.4085^{j}$ \\
$(0.0008)$ & $(0.0014)$ & $(0.0008)$ & $(0.0002)$ & $(0.0276)$ & $(0.0004)$ & $(0.0038)$ \\
\hline
\end{tabular}

NOTES: a - Parameter multiplied by 10; b - Parameter multiplied by 100; c - Parameter multiplied by 1,000; d - Parameter multiplied by 100,000; e - Parameter multiplied by 1,000,000; f - Parameter multiplied by 100,000,000; g - Parameter divided by 1,000; h - Parameter divided by 10,000; $\mathrm{i}$ - This is the annual interest rate; $\mathrm{j}$ - Parameter in text is an exponential transformation of this. 